\title{
A priority-based approach for satisfying the diverse users' needs, capabilities and expectations: a universal kitchen design case
}

\author{
Yasemin Afacan ${ }^{\mathrm{a} *}$ and Halime Demirkan ${ }^{\mathrm{b}}$ \\ ${ }^{a}$ School of Planning, Architecture and Civil Engineering, Queen's University Belfast, David Keir Building \\ Stranmillis Road, Belfast BT9 5AG, UK; ${ }^{b}$ Department of Interior Architecture and Environmental Design, \\ Faculty of Art, Design and Architecture, Bilkent University, Bilkent, Ankara 06800, Turkey
}

(Received 16 August 2008; final version received 31 August 2009)

\begin{abstract}
Universal design process is a multi-constraint task due to many user requirements and the complexities caused by the interaction of the requirements in developing design solutions. Since all universal design requirements cannot be equally satisfied, a designer must determine the relative importance and implementation order of each requirement. Prioritisation of requirements is needed, not just to ignore the least important but also to guide designers while coping with dependencies, conflicts and trade-offs between multi-attribute requirements simultaneously. Thus, this study proposes a priority-based approach for satisfying diverse users' needs, capabilities and expectations in a design process conducted in a computer environment. The planning game technique and the analytic hierarchy process technique using a cost-value approach are the two techniques that are applied in prioritising the diverse requirements. The derived priority information is incorporated into a CAD interface with a developed plug-in tool. A universal kitchen design is chosen as a case study for the priority-based approach. The results of the acceptability studies indicate that the proposed plug-in tool is found useful, understandable, efficient, helpful and satisfactory in universal design process and can be developed for various architectural design applications.
\end{abstract}

Keywords: universal design; user needs; planning game; analytic hierarchy process; kitchen design; computer-assisted design

\section{Introduction}

Universal design as a problem-solving act is a cognitively challenging task (Story et al. 1998, Story 2001, Levine 2006). The sequence of cognitive design actions throughout the universal design process rests on a continuous process of interactions between the formulation of problems and the generation of alternative solutions (Ostroff 2001). Hence, the universal design process is considered as a multi-constraint task because of the many user requirements and the complexities that are caused by the interaction of these requirements while developing possible design solutions (Afacan 2008b). There are an important number of interacting and variable design elements that should be considered in a design process in order to satisfy the users' needs in a given environment. Moreover, determining the requirements, especially in the conceptual design phase, becomes a very difficult process because of the imprecise and uncertain specifications and prioritisations of

*Corresponding author. Email: y.afacan@qub.ac.uk

ISSN 0954-4828 print/ISSN 1466-1837 online

(C) 2010 Taylor \& Francis

DOI: $10.1080 / 09544820903303423$

http://www.informaworld.com 
diverse user needs. These can be elaborated in the following two design cases: designing large office blocks for all, during which 'there is interdependence between the workplace components, the working persons, their task requirements, the physical environment, the building characteristics and work performance' (Margaritis and Marmaras 2007, p. 782), and aerospace designing, in which there is always a complexity of requirements arising from the difficulty of creating more reliable and higher performance products better tailored to every individual customer's needs at ever lower cost (Clarkson and Hamilton 2000). Therefore, a successful universal design process, regardless of product, architectural or engineering design, is generally built on the basis of gaining a better understanding of the real user needs in relation to the design context (Darses and Wolff 2006, Clarkson et al. 2007). However, the extent of diverse user needs, the relevant time and the way of integrating universal design requirements to architectural design process still remain largely unresolved. Since all the universal design requirements cannot be equally satisfied during the design process, the designer must determine the relative importance and implementation order of each requirement. A requirement priority is needed, not just to discard the least important requirement but also to guide designers while simultaneously coping with user need conflicts and impairment trade-offs between multi-attribute requirements. Choosing candidate requirements for implementation and establishing their degrees of importance are primary determinants of user satisfaction (Karlsson and Ryan 1996).

Despite the extensive literature on requirements specification and prioritisation in software development, requirements engineering and product design fields (Holbrook 1990, Byun 2001, Isiklar and Büyüközkan 2007, Lin et al. 2008a), the universal design literature lacks systematic procedures and methods that effectively identify, prioritise and express user needs in built environments and interior spaces (Canadian Human Rights Commission 2006, The Center for Universal Design 2007a, 2007b). Although the process of selecting the appropriate set of universal design requirements is difficult, complex and multi-faceted, most universal design resources do not provide insight for the requirement-driven design activities, such as elicitation, documentation and validation (Choi et al. 2006, Demirkan 2007). Thus, the universal design as a decision-making process still relies heavily on subjective and empirical priority assessments by designers. In order to overcome these gaps in universal design practice, this study aims to propose a priority-based approach that is based on the hybridisation of the two techniques: the planning game (PG) technique (Beck 1999) and analytic hierarchy process (AHP) technique using a cost-value approach (Karlsson and Ryan 1997, Saaty 1980). Moreover, an interface tool that supports designers while dealing with the complexity of derived priority information during the conceptual design phase is developed. A universal kitchen design is chosen as a case study to demonstrate the application of the priority-based approach. The novelty of this study lies in the application of a prioritisation technique from the engineering design to a universal design case in the architectural design context, where little research has been found in literature, and furthermore in the incorporation of the derived priorities into a CAD environment. In this respect, this study contributes to engineering design literature by addressing two fundamental research issues: (1) it addresses a universal design challenge by focusing on the process of selecting the appropriate set of universal design requirements related to the diverse user needs, capabilities and expectations and (2) it expands finding new techniques for gaining and measuring requirements into the development process of a novel and transferable computer-based universal design tool.

\section{An overview of requirement prioritisation techniques for universal design}

Prioritisation of requirements requires a complex context-specific decision-making process. The term priority can be defined in some cases as the quantity and/or the importance of a requirement, 
while in other cases it is determined by how soon a requirement should be implemented (Lehtola et al. 2004). Because of the challenging nature of the prioritising process, there exist a number of different techniques for requirements' prioritisation in engineering domains that can be analysed in two categories with respect to their usage of scale (Karlsson et al. 1998, Karlsson et al. 2007). The first category involves techniques that result in priorities on an ordinal scale and provide a ranked order among requirements, e.g. the numerical assignment, the PG, the quality function deployment (QFD), the bubble sort and the binary search tree (Beck 1999). The techniques in the second category provide the results on a ratio scale with the information on how important one requirement is relative to the other: such as the AHP, the Wiegers method and the 100\$ test (Saaty 1980, Wiegers 1999, Leffingwell and Widrig 2000). According to Karlsson (1996), an efficient and accurate prioritisation technique should give a designer the following advantages: (a) a clear means for selecting the appropriate set of requirements for implementation; (b) support to resolve the conflicts between requirements and (c) support to evaluate the alternative design solutions. In this respect, in addition to the ranking of the requirements, a decision-maker also needs to know the relative distance between the ordered requirements to achieve an effective trade-off (Liu 1998). Therefore, it is concluded that for a more accurate and informative prioritisation process using solely an ordinal scale technique cannot be adequate in terms of analysing trade-offs and assigning a relative importance to each requirement. Similar to software design and requirements engineering, the requirements in the universal design process are complex, volatile, vast and multi-faceted so that a manageable prioritisation process, which can handle increasing number of requirements, is considered of a high importance (Ozkaya and Akin 2006). In literature, there are studies that applied QFD techniques in determining the universal design requirements, but not as a prioritisation process (Demirbilek and Demirkan 2004). Thus, to be able to propose a suitable prioritisation technique for a defined set of universal design requirements, the study selected the appropriate techniques from each category that were found to be suitable for this case as reported in the literature. The PG technique was chosen for ease and speed of use, and the AHP technique for its precision, ability to be combined with other techniques and capacity for systematic formulation of complex requirements that is suitable for handling the universal design requirements. The following three sections introduce briefly the selected prioritisation techniques: namely the PG (Beck 1999), the AHP (Saaty 1980) and the modified AHP using the cost-value approach (Karlsson and Ryan 1997). Finally, the last section elaborates on the proposed hybrid prioritisation technique. Each of these techniques provides an ordered priority list of requirements as the outcome.

\subsection{The PG technique}

The PG technique is recognised as the most traditional and well-known requirements prioritisation technique in practice (Lehtola and Kauppinen 2006). This technique uses the sorting algorithm in assigning requirements to one of the three categories described as essential, less essential and nice. The essential category includes desirable requirements, without which the system will not function; the less essential category has requirements that provide a significant value and the final category includes requirements that are nice to have with respect to the system performance (Beck 1999). The PG technique is an easy and straightforward technique, in which 'the requirements are presented as a ranking on an ordinal scale without the possibility to see how much more important one requirement is than another' (Karlsson et al. 1998, p. 146). Moreover, it is helpful in determining the requirements of the following phase with the possibility of combining priorities and technical issues in a short time (Beck 1999). It is also referred to Priority Groups, in which requirements are assigned to one of the three priority groups designated as high, medium and low according to their importance (Karlsson et al. 1998). 


\subsection{The AHP technique}

The AHP technique, originally proposed by Saaty (1980), is a leading prioritisation technique in the multi-criteria decision-making process (Vaidya and Kumar 2006). This technique uses pairwise comparisons for all possible pairs of requirements, in each structured hierarchical level. The original scale used by Saaty (1980) for pair-wise comparisons was a 1-9 point scale with the numerical counterparts $1 / 9,1 / 8, \ldots, 1 / 1, \ldots 8 / 1,9 / 1$, in which $1 / 9$ means that the value of one requirement is nine times smaller than the value of another and correspondingly, while $9 / 1$ indicates that the value of one requirement is nine times bigger than the value of another. The primary aim in assigning a relative importance to each requirement is to derive the overall requirement priority for each alternative solution in order to determine the best solution.

The AHP technique is composed of four steps. The first step is to construct a matrix $(n \times n)$ that is composed of rows and columns with the total number of requirements $(n)$. The second step is to perform pair-wise comparisons of all requirements according to the chosen criterion. For each pair of requirements, the relative intensity value is assigned to the corresponding matrix cell. Each cell in the main diagonal of the matrix has the value of 1 , since each requirement is compared with itself. For a matrix of the order $n, n(n-1) / 2$ comparisons are required. The third step is the normalisation of the matrix. Dividing each element in the matrix by the sum of that column normalises the columns and dividing each row sum with the number of requirements normalises the rows. As the final step, the relative priority value of each requirement is assigned according to the estimated eigenvalues. The eigenvalue can either be computed manually or by using a computational medium that automates the calculation process. Moreover, the consistency ratio (CR) of each matrix is calculated in order to validate the prioritisation (Saaty 1980) where the measure of consistency is called the consistency index (CI). The relevant index should be lower than 0.10 to be accepted as consistent. If the AHP ends with an inconsistency among requirements, the pair-wise comparisons should be made again to improve the consistency for an acceptable decision.

\subsection{The modified AHP technique: A cost-value approach}

While prioritising requirements through pair-wise judgements, there are also other requirement interdependencies different from value, such as risk, benefit, time, opportunity and cost that influence the decision processes and affect the performance of the overall system. Thus, in literature there are studies on modified AHP techniques that are involved with further developments in the use of comparison matrix and priority values (Vaidya and Kumar 2006). One of the most wellknown developments is a cost-value approach by Karlsson and Ryan (1997). In the cost-value approach, one determines the relative weight of each requirement in percentage according to its value and cost ratio. 'Value' is defined as the amount of contribution of each requirement to user satisfaction and corresponds to how important a decision-maker finds the requirement; whereas 'cost' is the amount of budget needed for implementing each requirement and corresponds to how much cost a decision-maker considers it adds to the overall design (Karlsson and Ryan 1997). After first comparing all requirements pair-wise according to their value, and later according to their cost, the results can be depicted in a graph. Three priority categories of requirements are calculated by using Equation (1) and the graph is divided into three areas designated as high, medium and low (Figure 1) as follows:

$$
\begin{cases}y / x \geq 2 & \text { if a requirement has high priority } \\ 0.5 \leq y / x<2 & \text { if a requirement has medium priority } \\ y / x<0.5 & \text { if a requirement has low priority }\end{cases}
$$

where $x$ is the cost in percentage and $y$ is the value in percentage. 


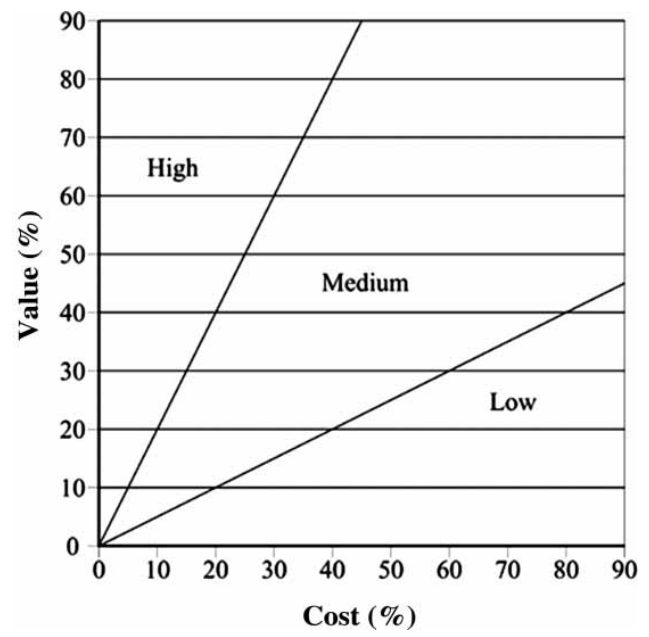

Figure 1. The cost-value graph depicting the three contribution areas.

\subsection{The hybrid prioritisation technique}

Although all the three above-mentioned techniques successfully assist in the decision-making process of constructing a hierarchical structure of a system, they do not reduce the time-consuming nature and laboriousness of the prioritisation process. The existing techniques take into account the ranking process only to a limited extent. Since in the AHP technique, the number of ranked pairs grows quadratically with the number of requirements, decision-makers find the ranking process more demanding, which causes trouble and inaccuracies in judgements. In this respect, a more recent study by Karlsson et al. (2007) recommended that it could be valuable and worthwhile to combine the AHP technique with the PG technique to conduct pair-wise comparisons, having distributed the requirements into the three priority categories of the PG. 'When the requirements have been ordered in a priority list using the PG it would be possible to compare each requirement to the one below it in the list and assign a number to their internal relation' (Karlsson et al. 2007, p. 28). The PG technique can be used with a ratio scale, and consequently the AHP technique can be applied with a reasonable amount of effort and manageable number of pairs. Compared with the previously described techniques, this gives the opportunity to present requirements in an ordinal scale and achieve an overview of the trade-offs among the requirements in the form of the PG categories before conducting the pair-wise comparisons. Thus, in order to meet the challenge of the universal design problem-solving context, this study is based on the hybridisation of the two techniques: namely the PG and the AHP, using a cost-value approach. The main issue in utilising the PG within an AHP framework is to evaluate the universal design requirements easily and systematically within a short time. The PG technique is found to be more efficient while being less time-consuming and easier to use in comparison with the AHP technique in the experiments of Karlsson et al. (2007). Time consumption is the measure of the average time required by a decision-maker to complete all stages of a prioritisation process, and ease of use is the measure that describes how easy it is to use a prioritisation technique (Karlsson et al. 1998). In the study, the original integer 1-9 scale proposed by Saaty (1980) is also modified into a more convenient 1-5 scale because of the findings stated in the previous studies: firstly, according to Zhang and Nishimura (1996) using a 1-5 scale was better than using 1-9 scale to express human views and reduce the time required to handle inconsistency in the decision-making process. Secondly, most of the recent studies pointed out the weakness of the AHP technique due to the ambiguity and misunderstandability of its original 
1-9 scale (Lin et al. 2008b). Hence, the proposed technique allows one to discuss the appropriate amount of effort that should be spent on each requirement much more objectively so that decision-makers are not doubtful of the reliability of the technique. This is because the resulting relative value and cost of each requirement is based on a ratio scale and always adds up $100 \%$ (Saaty 1980). In this respect, the technique enables versatile and deep analyses of a problem through the use of cost-value diagrams. These diagrams are useful and informative in identifying important requirements that are necessary for an alternative universal design solution. It should be noted that in the proposed technique several criteria, such as aesthetics, performance, usability, resources, design time and risk, are not included in calculating each requirement's value and cost. The overall structure of the proposed hybrid prioritisation technique is explained in the following section.

\section{Methodology}

This study consists of three main stages and is applied to a universal kitchen design case as seen in Figure 2. The first stage involves the elicitation of diverse kitchen user needs. First, a survey instrument is developed to engage with diverse user groups and discover how their needs are correlated with each other. Later, a factor analysis of the survey responses is done to construct the universal kitchen factors. In the second stage, the hybridisation of the PG with the AHP technique using a cost-value approach is carried out. As seen in Figure 2, in the first step of the second stage, the universal kitchen factors are defined on the basis of factor analysis as universal kitchen requirements (UKRs) and their corresponding items as sub-UKRs. In the second step, the PG technique is carried out with universal design specialists where each UKR is distributed into the high, medium or low PG categories. Having completed the PG, each specialist continues the

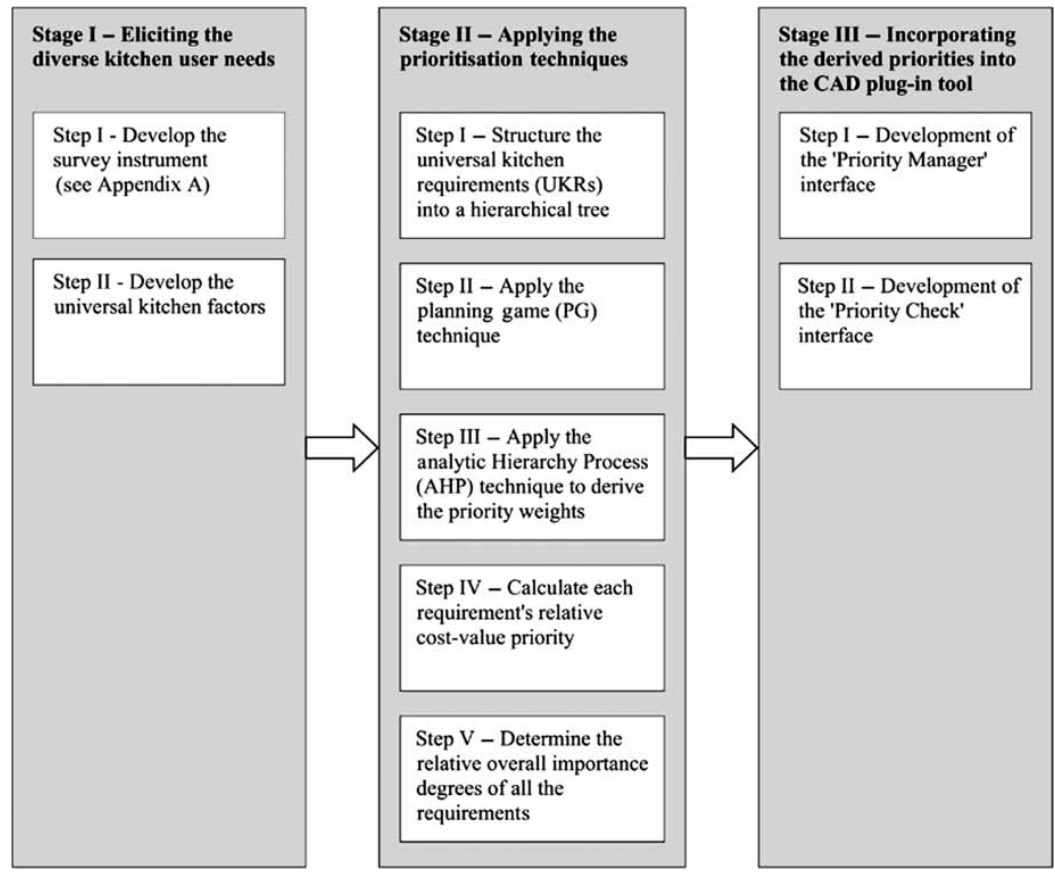

Figure 2. The three stages of the study. 
prioritisation process with the AHP technique using the cost-value approach. First, the pair-wise comparisons of the six UKRs under the high, medium and low PG categories and later, the pair-wise comparisons of all the sub-UKRs are performed by using a 1-5 scale. In the fourth step, the pair-wise comparison judgements both for value and cost are independently entered in the matrices and the priority weights of the requirements are calculated by using the computing tool MATLAB $^{\circledR} 7.4$ Release 2007. In the fifth step, the global weights of the sub-UKRs are calculated. The final stage is the incorporation of the derived priorities into a CAD environment, SketchUp software. The primary goal of this stage is to provide an integrated CAD medium, where designers can be informed about the cost-value ratios of each UKR and sub-UKR during analysis, synthesis and evaluation operations of universal kitchen design solutions. The next sections explain each stage in detail.

\section{Stage I: eliciting the diverse kitchen user needs}

Compared with well-defined problems, such as a 15-puzzle (Akin 1986), which have clear goals and known ways of proceeding that lead to an answer (Cross 1989), architectural design problems, such as a universal kitchen design, can be characterised as ill-defined problems. This is because many components 'support the idea of individualisation and personalisation through design flexibility and diversity; that is, different designs for different users within the same system, or adaptability and adjustability that can accommodate all users' (Mullick and Levine 2001, p. 41.3). Moreover, kitchen designs are not the same as other universal design problems because of the limited flexibility in appliances and work layout (Wellcome Home Project 2007). The most particular challenge associated with a universal kitchen design is that it does not prescribe a final state, it is ongoing and its solutions are never finished (Mullick and Levine 2001). Therefore, rather than being a generic, mass-produced environmental product, which is designed only by integrating cabinets, fixtures and appliances, a universal kitchen is an environment that is composed of a variety of strongly correlated products. Hence, most kitchen designs today are non-inclusive and do not allow equal participation of all family members (Mullick and Levine 2001). During the universal kitchen design process, the designer is responsible for exploring the correlations between user needs and design specifications. While able-bodied users experience minimal difficulties, children, pregnant women, the elderly, people with physical, visual and/or hearing impairments and seated users face diverse challenges regarding kitchen layouts, such as gaining access to cabinets and storage areas, reaching counters, using appliances and operating controls (Mullick and Levine 2001). The demand for universal kitchens has increased as the society has been transformed by demographic change: there are more people now with impairments than ever before. Today's kitchens in the private housing context are different to 1940s kitchens, in which the mother was the exclusive user (Hayden 1972); they are necessarily multi-user because all the family members use the kitchen. Such a paradigm shift has a huge impact on the inclusive design community regarding design, construction, marketing, usage and maintenance of future kitchens (Canadian Human Rights Commission 2006). Therefore, the multi-user nature of kitchens in the private housing context encompasses the complexity of design activities that require an inclusive understanding. Designers should be informed about user needs and capabilities as early as possible in order to address all these challenges and create an ideal kitchen environment. Providing a systematic approach for a cost-effective universal kitchen design is highly related to the initial elicitation of user needs. Note that the kitchen should not be considered in isolation from a living environment, rather it is the most used place in the home (Mullick and Levine 2001). Since this study is only limited to interior design applications, it considers the kitchen on its own within the given size and shape of a physical space. 


\subsection{Step I: develop the survey instrument}

Although there are guidelines and accessibility standards, designers have difficulty in reading and sorting the academic sources of information (Gregor et al. 2005). Most of the user information is presented in textual and numerical form, which needs interpretation to be incorporated into a design project (Carmichael et al. 2007). Moreover, user needs are often expressed in imprecise and non-technical terms so that there are often undiscovered needs and mismatched design requirements (Afacan and Erbug 2009, Carmichael et al. 2007). In order to overcome these elicitation inadequacies, the study developed a survey instrument with a comprehensive list of 87 items for an inclusive kitchen environment (Appendix 1). The instrument includes kitchen design features that contribute to or can be components of a promising universal kitchen solution. It is based on a structured questionnaire format with close-ended questions. The 87 items comprises both international universal design and human factors design resources presented in literature (Grist et al. 1996, Goldsmith 1997, The Center for Universal Design 2000, Mullick and Levine 2001, Young and Pace 2001, Beecher and Paquet 2005, Canadian Human Rights Commission 2006, Afacan 2008a, 2008b). During the survey, the users were asked to rate their importance levels for each item on a scale of 1-5 (1 being the least important and 5 the most important) and to mark the appropriate boxes to identify how important is each of the following features is working successfully within a kitchen environment.

The survey was conducted with a total of 135 kitchen users who were living in privately owned housing and were selected by random sampling, including 45 adults (between ages 28 and 58), 45 elderly (between ages 65 and 97) and 45 adults with impairments including 25 physically impaired adults (between ages 28 and 51) using wheelchairs $(n=13)$, crutches $(n=7)$, prostheses $(n=3)$ and sticks $(n=2)$ as mobility aids and 20 visually impaired adults (between ages 30 and 59) having total loss of sight $(n=8)$ and mild loss of sight $(n=12)$. This sample group is representative of kitchen users in the privately owned housing context, where all the family members use the kitchen and the overall kitchen design should be adaptable to suit different installations. To be sure that the sample group was representative, first a pilot study was conducted with the same users and the results were analysed and discussed by the two universal design specialists, one industrial designer (S1) and one architect (S7), who later took part in the prioritisation stage. During the survey, the data were collected during face-to-face surveys with all the participants. At the beginning, a brief summary of the procedure and the aim of the study were explained. The survey lasted from 60 to $75 \mathrm{~min}$ for each participant. Moreover, during the survey an unstructured interview was also conducted with each participant, which helped to discuss the results in a more comprehensive way. Furthermore, to avoid any biases participants were not allowed to listen to others while they were surveyed (Table 1).

Table 1. The demographic characteristics of the nine universal design specialists.

\begin{tabular}{|c|c|c|c|c|c|}
\hline \multirow{2}{*}{$\begin{array}{l}\text { Specialist } \\
\text { no. }\end{array}$} & \multirow[b]{2}{*}{ Profession } & \multirow[b]{2}{*}{ Age } & \multicolumn{2}{|c|}{ Gender } & \multirow{2}{*}{$\begin{array}{c}\text { Professional } \\
\text { experience }\end{array}$} \\
\hline & & & M & $\mathrm{F}$ & \\
\hline $\mathrm{S} 1$ & Industrial designer & 51 & $\mathrm{X}$ & & 20 \\
\hline $\mathrm{S} 2$ & Industrial designer & 39 & & $\mathrm{X}$ & 10 \\
\hline S3 & Industrial designer & 48 & & $\mathrm{X}$ & 22 \\
\hline $\mathrm{S} 4$ & Interior architect & 38 & & $\mathrm{X}$ & 12 \\
\hline S5 & Interior architect & 44 & & $\mathrm{X}$ & 14 \\
\hline S6 & Interior architect & 36 & $\mathrm{X}$ & & 10 \\
\hline S7 & Architect & 52 & $\mathrm{X}$ & & 30 \\
\hline S8 & Architect & 40 & $\mathrm{X}$ & & 18 \\
\hline S9 & Architect & 43 & $\mathrm{X}$ & & 15 \\
\hline
\end{tabular}




\subsection{Step II: develop the universal kitchen factors}

Before carrying out the factor analysis to determine the universal kitchen factors, the uninformative and irrelevant survey items were eliminated using two refinement factors: (a) extreme value effects and (b) the strength of correlation scores. An extreme value effect can occur if the response means for each item are lower and/or higher than they should be (Krathwohl 1997), i.e. they are at the extreme ends of the scale used. In the study, the items having mean score lower than 1.50 and higher than 4.50 were considered as the extreme values. The frequency analysis of the survey indicated that the survey items $13,70,72,75$ and 77 , which have mean scores of 1.20, 1.17, $1.40,1.40$ and 1.36, respectively, were excluded from the further data analyses. Calculating the Pearson product-moment correlations and constructing a correlation matrix, the strength of the correlations among the response items was investigated. In the study, all the correlations between the items were greater than 0.30 .

The ratings of the participants on 82 items were analysed by using the Statistical Package for the Social Sciences (SPSS). First, exploratory factor analysis was used to carry out data analysis. By using the Varimax method, which is a most frequently used rotation option (Howitt and Cramer 1999), a rotated component matrix was constructed, which indicated the extracted factors with their factor loadings. The factor loadings greater than 0.71 were considered as highly correlated, and the ones below 0.71 were excluded. Moreover, the factors including less than three items were removed to avoid a poor correlation structure. In this respect, the factor analysis resulted in a six-factor solution that accounted for $64.048 \%$ of variances (Table 2). Since a factor is usually identified according to the item with the highest factor loading (Bailey 1994), the factor names were based on the items with the highest loading value.

These six-factor scales were also arrived at by their correspondence with seven universal design principles; Principle 1: equitable use; Principle 2: flexibility in use; Principle 3: simple and intuitive use; Principle 4: perceptible information; Principle 5: tolerance for error; Principle 6: low physical effort and Principle 7: size and space for approach and use (The Center for Universal Design 1997). Figure 3 illustrates the relationship between the six factors and seven universal design principles. A good universal kitchen requires a thorough understanding and demonstration of these principles (Wellcome Home Project 2007). To cope with diverse type of impairments and physiological decline in increasing age, users should be better supported with respect to varying abilities in all domains, including vision, hearing, strength, dexterity and cognition. For example, bad posture, which means improper alignment of the body due to prolonged sitting/standing or abnormal movements (Pinto et al. 2000), causes excess mechanical stress on the joints and muscles and should be avoided. It is also essential to eliminate inconsistent lighting levels, which impair visual functioning.

Moreover, interpretations from the unstructured interviews gave much more inclusive feedback to elucidate diverse user needs and systematise the user data under each factor scale. For Factor 1 , all the elderly participants emphasised the importance of operating control features without repeated movements in order not to cause pain. However, all the adults and participants with

Table 2. Summary of the rotated factors.

\begin{tabular}{llccc}
\hline Factor & \multicolumn{1}{c}{ Scale } & Eigenvalue & Variance $(\%)$ & Cumulative $(\%)$ \\
\hline 1 & Operation of controls with low effort & 17.765 & 21.665 & 21.665 \\
2 & Appropriate counter heights and spaces & 15.788 & 19.253 & 40.918 \\
3 & Operation of controls with clear information & 10.440 & 12.731 & 53.649 \\
4 & Adequate illumination & 4.029 & 4.913 & 58.562 \\
5 & Ease of reach to oven & 2.282 & 2.783 & 61.345 \\
6 & Ease of reach to base cabinets & 2.216 & 2.703 & 64.048 \\
\hline
\end{tabular}




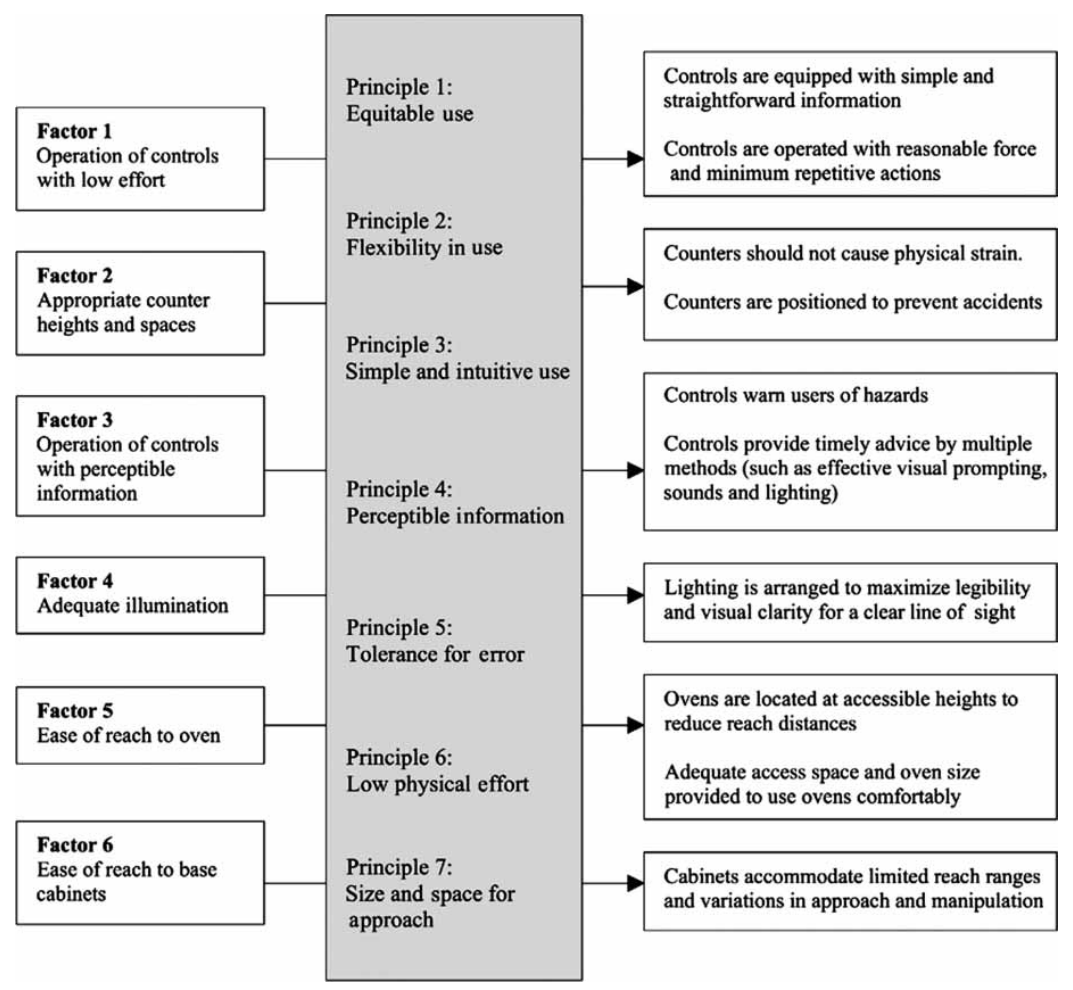

Figure 3. The relationship between the six factors and seven universal design principles.

impairments stated that the operation of controls with low effort was the least important issue while working efficiently in a kitchen. For Factor 2, all the participants with impairments highlighted the importance of a heat-resistant counter material since the visually impaired participants use their hands to touch/sense the counters while working and the physically impaired participants make use of the counter surface in order to stand up in a balanced manner. Hence, the counter surface should be without burn marks, impervious to the thermal shocks of hot foods and should not blister if a hot pan is put down on it. The experience of visual difficulties and limitations due to the aging process placed importance on Factor 3 for most of the elderly and participants with visual impairments, so that they complained of the non-provision of any compatibility features in the existing controls, such as colour contrasts, Braille markings, large-print readouts, audible and tactile feedback. Regarding Factor 4, the interviews were helpful in identifying adequate illumination levels as the key issue for maximising the function and enjoyment of a kitchen for all since all the participants regardless of the age and ability stressed the quality of light. For Factor 5, the statements of all the physically impaired participants indicated the importance of close access to ovens with an appropriate counter space on at least one side of the oven. Interviews associated with Factor 6 indicated the essential need for maximising the storage space capacity within easy reach and minimising the number of movements from one area to another, because low and/or rear portions of base cabinets are unusable due to the limited visual and physical ability of the participants with impairments.

The study also utilised ANOVA analyses with Bonferroni post-hoc comparisons on each factor scale score and calculated the $F$-ratio in order to analyse whether the scale means of the user groups were significantly different from each other. Except Factor 4, 'Adequate illumination', whose means between the four users groups were close to each other $(F=2.593, d f=(3,12), p=$ 0.320 ), the study found statistically significant differences between the user groups. ANOVA 
on scale scores indicated two important issues. The first is the parametric characteristic of the factors, which is related to design situations where requirements are not in conflict with any of others, and the second is the correlation difference of each factor in terms of the diverse user groups, which is related to design situations where requirements are in conflict with each other. The presentation of the six-factor scales in the set of parameter correlations indicated that achieving a successful universal kitchen design solution necessitates the consideration of each factor simultaneously with its factor loadings. It is not adequate to respond to a selective set of factors in order to create a universal kitchen. For example, the requirement of 'Adequate illumination' does not cause a conflict; on the contrary, it is directly correlated with others in terms of a design criterion (Factors 1-3, 5 and 6). Hence, it is not possible to ensure an adequately illuminated kitchen by only providing adequate natural and artificial light. It also depends on the task lighting above counters, cook-tops and inside cabinets, where legibility and visibility are required (Factors 2, 5 and 6). Moreover, it is also closely intertwined with adequately illuminated electrical sockets and switches to make them easy to read and operate (Factors 1 and 3). The second issue is the significant differences between the user groups with respect to each factor. The physical and visual impairment of a user significantly affects her/his importance rating of the items. The kitchen needs for able-bodied users and users with impairments are in conflict. Furthermore, the elderly users significantly differ from the rest of the group. Due to the aging process, they experience various physical and/or visual limitations; therefore, they need increased functionality and usability in kitchens. For example, while most of the adults, 35 of 45, reported that they could easily reach to the low levels of base cabinets, all the elderly participants had reach limitations. The participants with wheelchairs, crutches and canes also found bending over and lifting a kitchen object from an inaccessible base cabinet difficult. Furthermore, most of the visually impaired participants, 16 of 20, experienced difficulties in seeing all contents of base cabinets and suggested that strip lighting under cabinets can improve their visual functioning. Therefore, creating a universal kitchen can still be a very complex and time-consuming activity even with the developed universal kitchen factor scales. In order to overcome the complexity and effort required for designing a universal kitchen, the factor scales should be prioritised to assist designers in deciding which of the requirements are relatively more important than the others and thus should be implemented first.

\section{Stage II: applying the prioritisation techniques}

During the second stage, the hybrid prioritisation technique was applied. In each step of this stage, the choice of the relevant technique kept in view that designers are seeking systematic, efficient and effective ways to prioritise requirements because of the limited time and budget resources of a design project (Lehtola et al. 2004). Thus, time consumption, ease of use, clarity, accuracy and consistency become significant for a priority-based approach.

\subsection{Step I: structure the UKRs into a hierarchical tree}

Since the strength of the AHP lies in its ability to structure complex and multi-attribute problems (Saaty 1980), in the first step of the prioritisation procedure the AHP technique was applied to structure a universal kitchen hierarchy by using the derived six-factor scales. This hierarchy is depicted in Figure 4 as a tree diagram. The tree structure of the universal kitchen design problem involves a three-level hierarchy - a goal, a set of criteria and sub-criteria. Designing a universal kitchen as the main goal is at the top of the hierarchy; the six factor scales as the UKRs are in the second level and the sub-UKRs of each UKR at the bottom level. 


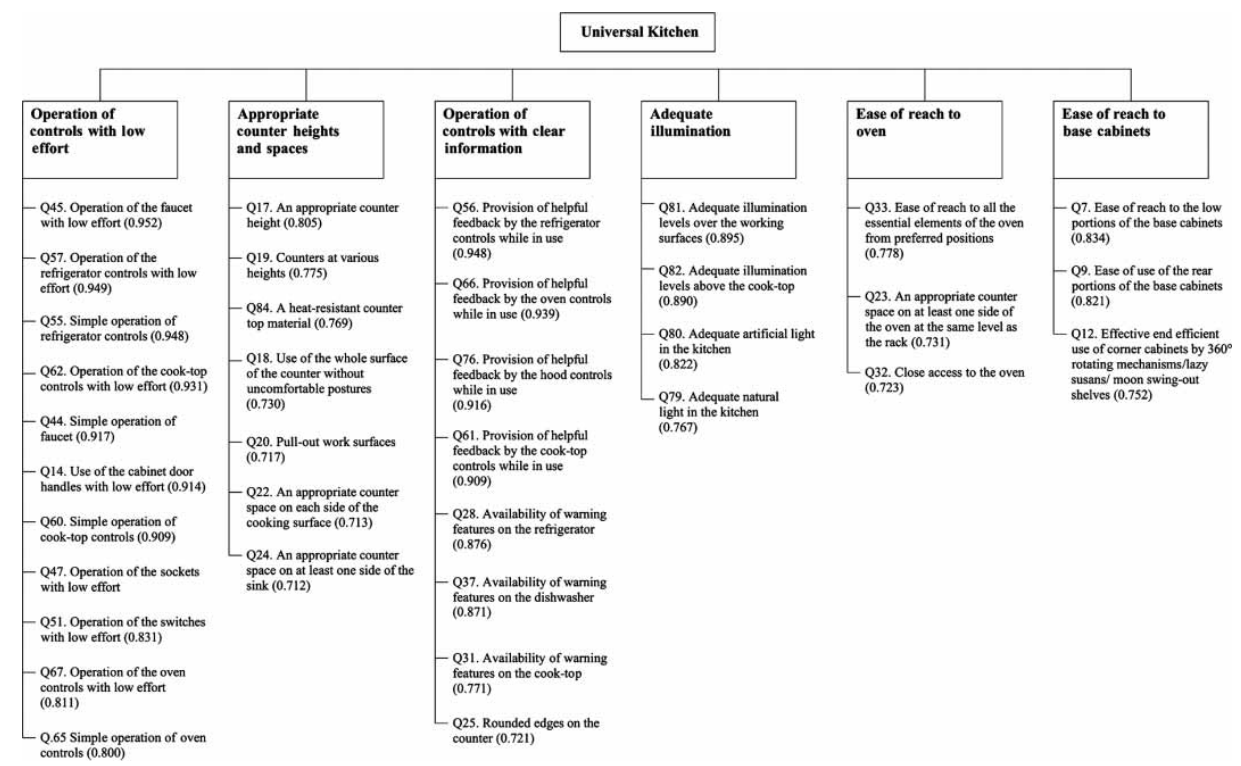

Figure 4. The hierarchical tree structure of the universal kitchen design problem including the factor loadings.

\subsection{Step II: apply the PG technique}

In this step, the PG technique was applied for each UKR at the second level. The PG technique was carried out with nine universal design specialists from different design disciplines; namely three industrial designers, three interior architects and three architects, comprising four females and five males with a professional experience ranging from 10 to 30 years (Table 1). These specialists are academicians, who teach universal design courses and deal with the universal design issues in both academic and professional life. At the beginning, a summary of the study was provided to each specialist and a short explanation about the application of the PG and AHP techniques was given. The prioritisation was performed individually and guided by the author. Each specialist was asked to prioritise the six UKRs into the three PG categories as high, medium and low. Brief instructions about each category were given to the specialists as the high category represents UKRs, without which the kitchen will not function universally and which therefore should be implemented as soon as possible; the medium category has UKRs that provide significant contribution to the universal kitchen and the low category includes UKRs that are nice to have with respect to the universal kitchen performance. In each prioritisation process, a different order of the UKRs was used in order to eliminate any order effects. To determine the corresponding category for each UKR, the mean values of the distributions by the nine specialists were calculated. The high PG category is composed of 'Appropriate counter heights and spaces' and 'Operation of controls with clear information'; the medium PG category 'Adequate illumination' and 'Ease of reach to oven' and the low PG category 'Operation of controls with low effort' and 'Ease of reach to base cabinets'.

\subsection{Step III: apply the AHP technique to derive the priority weights}

There were no time lapses between the PG and AHP technique applications. Having completed the PG technique, each specialist continued the prioritisation process with the AHP technique using the cost-value approach. First, each performed the pair-wise comparisons of the six UKRs under 
the high, medium and low categories and later, the pair-wise comparisons of all the sub-UKRs. The prioritisation for the UKRs included a total of three pair-wise comparisons for the value and cost, respectively: one for each of the high, medium and low categories. The pair-wise comparison judgements according to the value and cost were entered in $2 \times 2$ matrices. Six comparison matrices were constructed in total and their consistencies were checked as less than 0.10 and acceptable. Table 3 shows an example of the comparison matrix of the two UKRs in the high category according to the cost. The judgements are the mean values on a 1-5 scale with respect to the nine specialists.

The same prioritisation process was repeated for all the sub-UKRs. Each specialist made 116 pair-wise comparisons for the value and cost respectively: $(7 \times 6 / 2+8 \times 7 / 2)=49$ comparisons for the sub-UKRs under high PG category, $(4 \times 3 / 2+3 \times 2 / 2)=9$ comparisons for the sub-UKRs under medium PG category, $(11 \times 10 / 2+3 \times 2 / 2)=58$ comparisons for the subUKRs under low PG category. Twelve comparison matrices were constructed in total and their consistencies were checked as less than 0.10 and acceptable. Table 4 shows an example of the comparison matrix of the seven sub-UKRs under 'Appropriate counter heights and spaces' according to their relative value.

\subsection{Step IV: calculate each requirement's relative cost-value priority}

In this step, the derived priority weights of the requirements were plotted along the $x-y$ axis of the cost-value graphs using Equation (1). The priority categories illustrate which of the UKRs and sub-UKRs have high, medium and low contributions to the universal kitchen environment with respect to their cost-value ratio. First the UKRs and later all the sub-UKRs were represented in the cost-value graphs in order to analyse the ideal ratio of design requirements, which are the most valuable but the least expensive. For the cost-value analysis of the UKRs, one graph was constructed (Figure 5). The UKRs under the same PG category are represented with the same symbol. Three of the six UKRs are located in the high ratio area of the cost-value graph. Their value to the cost ratio is higher than 2. According to Figure 5, regarding the two UKRs in the high PG category, depicted as a rhombus symbol, 'Appropriate counter heights and spaces'

Table 3. The comparison matrix of the two UKRs under high category according to the cost.

\begin{tabular}{lccr}
\hline & $\begin{array}{c}\text { Appropriate counter } \\
\text { heights and spaces }\end{array}$ & $\begin{array}{c}\text { Operation of controls } \\
\text { with clear information }\end{array}$ & Weight \\
\hline Appropriate counter heights and spaces & 1.00 & 0.38 & 0.275 \\
Operation of controls with clear information & 2.66 & 1.00 & 0.725 \\
\hline
\end{tabular}

Note: $\lambda \max =2.005 ; \mathrm{CI}=0.005 ; \mathrm{RI}=0.000 ; \mathrm{CR}=0.00<0.100$.

Table 4. The comparison matrix of the seven sub-UKRs under 'Appropriate counter heights and spaces' according to the value.

\begin{tabular}{lllllllll}
\hline & Q17 & Q19 & Q84 & Q18 & Q20 & Q22 & Q24 & Weight \\
\hline Q17 & 1.00 & 4.66 & 2.66 & 2.33 & 2.66 & 0.33 & 0.44 & 0.175 \\
Q19 & 0.21 & 1.00 & 0.38 & 0.83 & 0.66 & 0.30 & 0.44 & 0.056 \\
Q84 & 0.37 & 2.66 & 1.00 & 2.66 & 3.66 & 0.44 & 0.5 & 0.133 \\
Q18 & 0.42 & 1.33 & 0.37 & 1.00 & 2.33 & 0.38 & 0.5 & 0.083 \\
Q20 & 0.37 & 1.66 & 0.27 & 0.42 & 1.00 & 0.25 & 0.38 & 0.057 \\
Q22 & 3.33 & 3.33 & 2.33 & 2.66 & 4.00 & 1.00 & 2.33 & 0.305 \\
Q24 & 2.33 & 2.33 & 2.00 & 2.00 & 2.66 & 0.42 & 1.00 & 0.191 \\
\hline
\end{tabular}

Note: $\lambda \max =7.550 ; \mathrm{CI}=0.091 ; \mathrm{RI}=1.320 ; \mathrm{CR}=0.069<0.100$. 


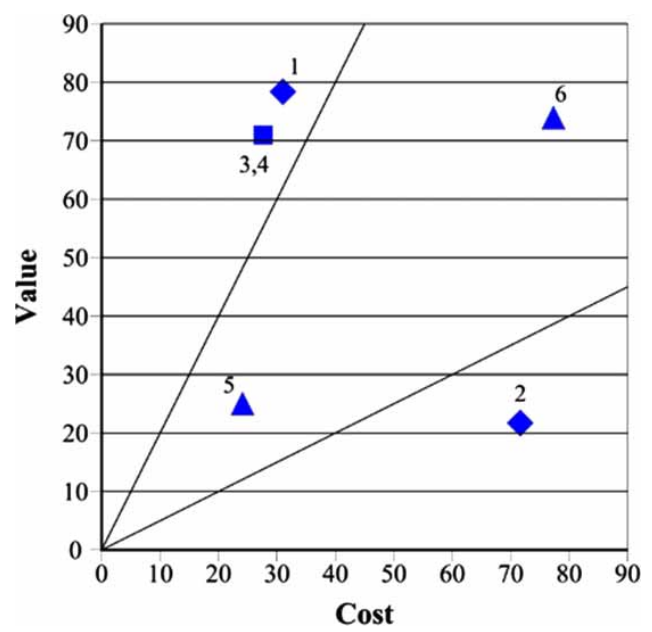

Figure 5. Cost-value graph for the six UKRs. Symbols correspond to the representation of the requirements under the same PG category.

has a higher value to cost ratio compared with 'Operation of controls with clear information'. If adequate attention and resources can be allocated to satisfy the counter requirements, then a higher level of overall satisfaction can be achieved in a kitchen. This is reasonable because satisfying this requirement will contribute to the satisfaction of the other UKRs. Thus, counterrelated design requirements should be implemented first. The reason for the high implementation cost of 'Operation of controls with clear information' is that those controls retrofitted for people with impairments are different to mass-marketed controls. Hence, they are more expensive, which makes their value to cost ratio high. Universally designed controls should become commonplace and their marketability should be enhanced. The two UKRs under the medium PG category, depicted by a square symbol, are in the high contribution area of the graph and have the same value to cost ratio, so their implementation priority does not matter. Both lighting design and oven design should be carefully planned because maximising the function in universal kitchens is highly related to the quality of light as well as the convenience of cooking appliances (Wellcome Home Project 2007). The last two requirements under the low PG category, depicted by a triangle symbol, are located in the medium contribution area and have nearly the same cost-value ratio. Therefore, the cabinet accessibility and control design can be considered together and implemented in the same order although cabinet-related requirements possess high cost.

For the cost-value analysis of all the sub-UKRs, a total of six cost-value graphs were drawn. The values of all the sub-UKRs were plotted against their estimated cost of implementation. Figure 6 indicates the cost-value graph of the seven sub-UKRs under 'Appropriate counter heights and spaces'. Addressing the height and area are the main universal design concerns when planning countertops (Q22, Q24 and Q17 in the high contribution area). Careful attention should also be paid to adequate work surface at specific work centres. Following the adequate counter space requirements, it is essential to design counters at various heights and select appropriate materials that are suitable to the needs of visually impaired people (Q19 and Q84 in the medium contribution area). Finally, the last two requirements Q18 and Q20, which are related to the comfortable use of counters and pull-out work surfaces, are in the low contribution area because of their high implementation costs. It is possible to significantly reduce the cost and duration of universal kitchen design by implementing the low contribution requirements at the end or replacing them with alternative features having higher value but lower cost. 


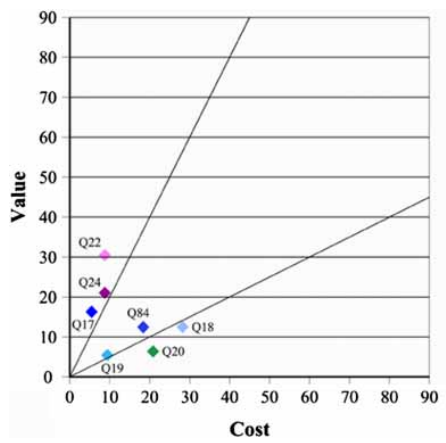

- Q17. An appropriate counter height

$\diamond$ Q19. Counters at various heights

$\checkmark$ Q84. A heat-resistant counter top material

Q18. Use of the whole surface of the counter without uncomfortable postures

$\checkmark$ Q20. Pull-out work surfaces

Q22. An appropriate counter space on each side of the cooking surface

$\checkmark$ Q24. An appropriate counter space on at least one side of the sink

Figure 6. Cost-value graph for the seven sub-UKRs under 'Appropriate counter heights and spaces'.

\subsection{Step V: determine the relative overall importance degrees of all the requirements}

The relative overall importance of one kitchen requirement to another is called its global weight, when all requirements are considered jointly with respect to the whole universal kitchen environment. During this step, the global weights of the sub-UKRs were given by multiplying the priority weight of each sub-UKR by the corresponding UKR. Appendix 2 summarises the global weights of the sub-UKRs under the three PG categories for value and cost, respectively. The sub-UKRs in Appendix 2 were ranked from the highest to the lowest ratio with respect to the drawn cost-value graphs.

\section{Stage III: incorporating the derived priorities into the CAD plug-in tool}

Lack of knowledge and tools for practicing universal design are the main identified barriers to putting universal design into practice (Goodman et al. 2006). Since most designers now use CAD tools extensively (Lawson 1998) and in the last 30 years attempts have been made to assist architects in performing their increasingly more demanding tasks through the use of computational methods' (Carrara et al. 1994, p. 147), it is highly appropriate to provide a support tool for universal design through this medium. Especially in the conceptual design phase, where various user needs and design requirements need to be quickly searched and evaluated, the use of a CAD tool can be very effective to deal with the incorporation of universal design ideas. For this reason, in the final stage of the priority-based approach, the study deals with incorporating the derived priority weights into a CAD environment. Having reviewed the related literature, the study developed a plug-in tool for SketchUp software, which is written by SketchUp Ruby API as an application language interface. The plug-in tool is constructed based on a typical structure model for a modern CAD system (Eastman 1999). It is composed of three main environments: modelling, application language and universal design (Figure 7). Each environment is composed of software modules, which have multiple inputs/outputs defined by arrows. Moreover, since SketchUp Ruby API is an object-oriented (OO) language, the tool is easily transferable, customisable and open to other universal design problems and innovative features when necessary through useful/additional new OO scripts. It enables users to adjust its capabilities to the requirements of a design problem. The reason for choosing SketchUp as a 3D modelling environment is its simple, flexible and customisable graphical interface features: it is an easy-to-use conceptual tool. Compared with other 3D modelling environments developed for the conceptual design phase, SketchUp provides support for a web-based collaboration design environment through Internet. It allows users effective modelling operations in extruding and sketching 2D shapes into 3D forms 


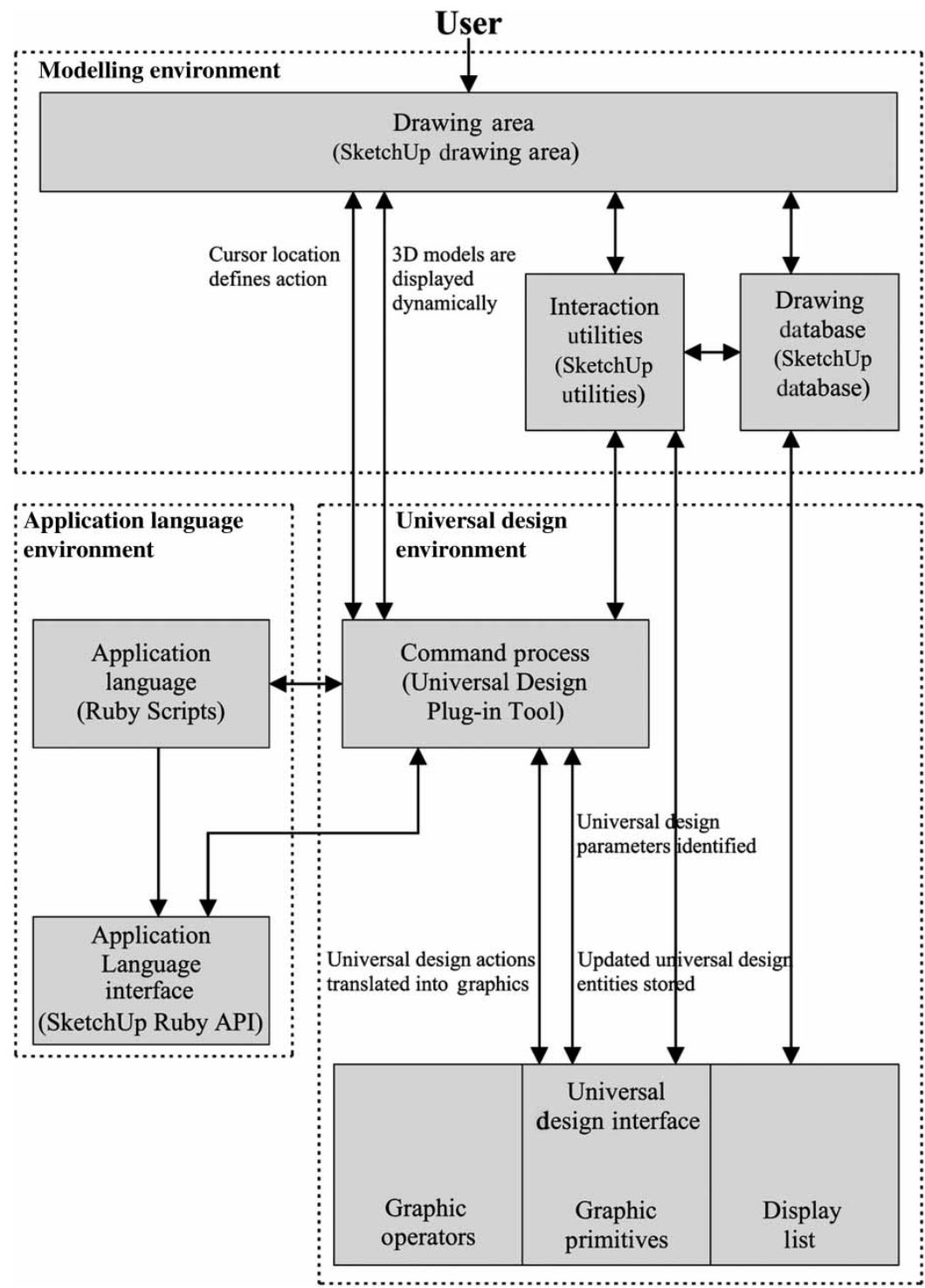

Figure 7. The structure of the developed plug-in tool.

rather than using conventional Boolean CAD methods, such as AutoCAD modelling operations (Eastman 1999).

The plug-in tool is composed of two interfaces: 'Priority Manager' interface and 'Priority Check' interface that can be accessed from the Plug-ins menu of SketchUp software program (Figure 8). They provide either a dialog box or web dialog box as an interface element. Through the 'Priority Manager' interface, designers can identify the necessary priority information from SketchUp drawing area. It acts as a filter database before analysing, generating and assessing universal kitchen solutions. The 'Priority Check' interface is used to check the solution against each of the six UKR priorities. Hence, the plug-in tool is capable of three actions: (1) it allows designers to develop a set of requirement priorities within a simple environment, (2) it evaluates the performance of a proposed solution and (3) it provides relevant information on design changes 


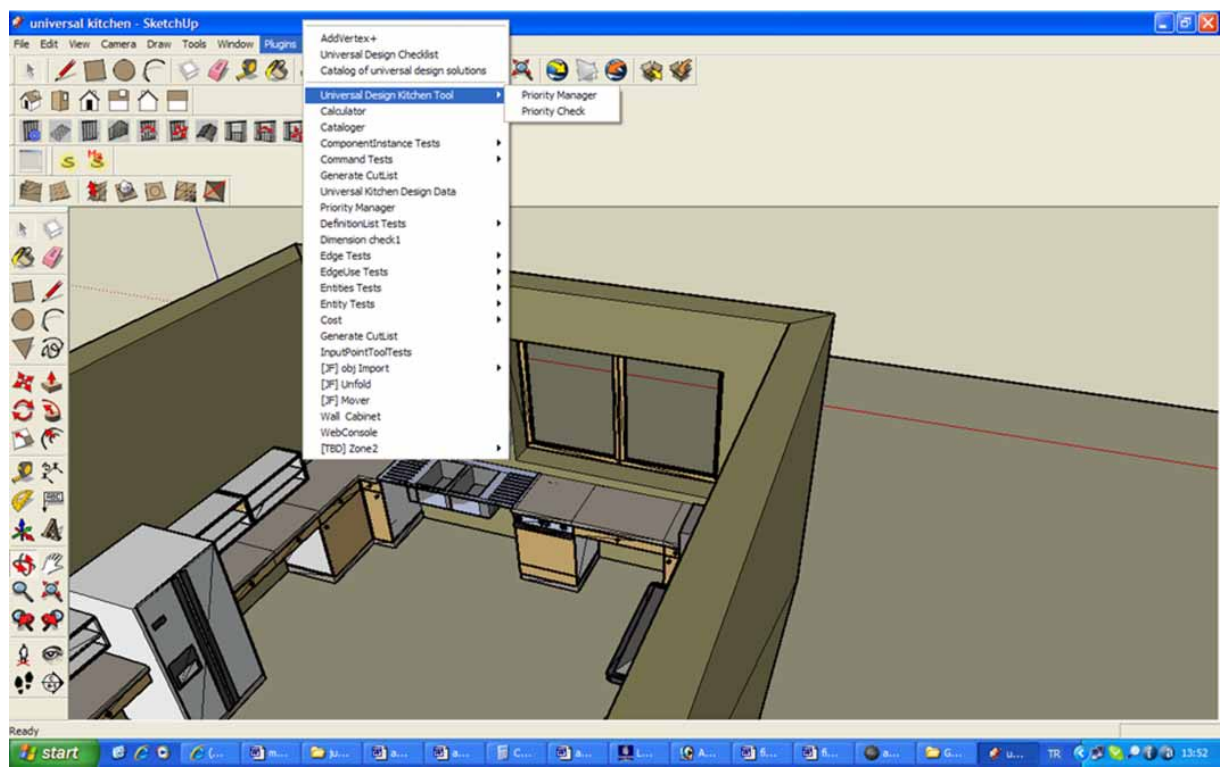

Figure 8. The screenshot of SketchUp drawing area showing the developed CAD plug-in tool under 'Plug-ins' menu.

to achieve a higher degree of user satisfaction. Thus, rather than reorganising the existing data, the 'Priority Manager' interface can respond to the dynamic nature of the design process by giving users the possibility of keeping track of the requirement priorities. Furthermore, the 'Priority Check' interface supports the evaluation stage of the design process by allowing users to go through all requirements and evaluate their appropriateness to universal design.

\subsection{Development of the 'Priority Manager' interface}

The 'Priority Manager' interface consists of navigation views of the UKRs and main information area of the related sub-UKR priorities with add/delete/edit options (Figure 9). The information area with a cost-value graph is reloaded each time when a user chooses a different UKR from the navigation view. The information area also provides designers the ability to edit/delete the existing sub-UKRs and/or add new sub-UKRs including their priority weights. Moreover, the interface can remain active while a user works on the SketchUp drawing area. Through this capability of the interface, designers have an access to the priority information at various design levels and at each relevant decision point. In this respect, the 'Priority Manager' interface is an input aid in representing, storing and retrieving the relevant priority information on kitchen requirements. Moreover, such an interface allows a designer to explore a kitchen design solution from various perspectives (value and cost), analyse trade-offs (what-if scenarios regarding the requirement priorities) and compare it with other candidate solutions.

\subsection{Development of the 'Priority Check' interface}

The 'Priority Check' interface supports the design process while evaluating in terms of universal kitchen design. Design and evaluation processes occur in parallel to support designers on demand, where the designer activates the 'Priority Check' interface either from the 'Plug-ins' menu or by right-clicking on the selected design feature for priority check (Figure 10). The data on the 'Priority Check' interface comes from the priority manager and is illustrated under the six sub-menu items 


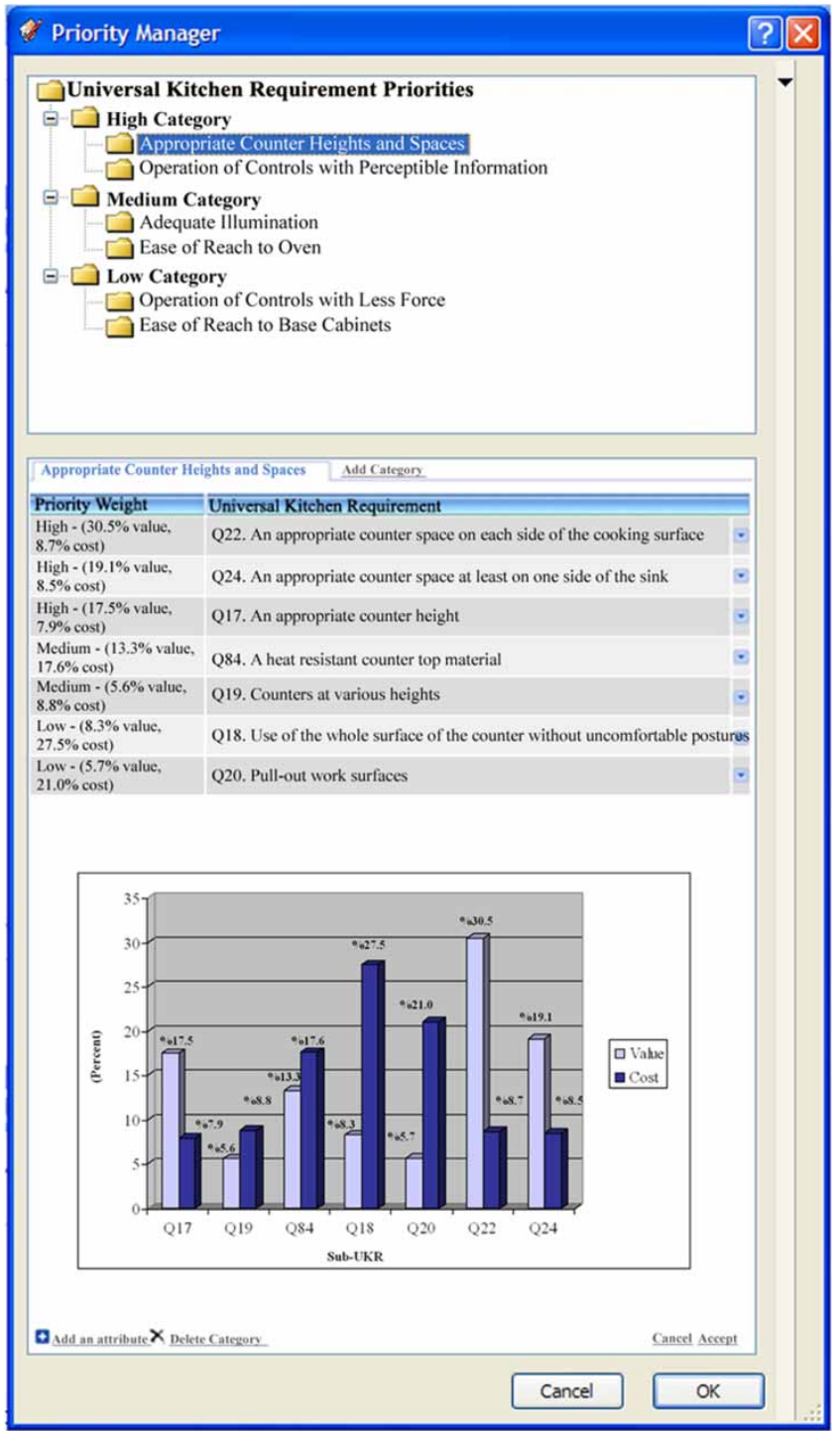

Figure 9. The 'Priority Manager' interface with navigation views of the UKRs and main information area.

each of which corresponds to one of the six UKRs. This interface allows the evaluation of design solutions while designers are engaged in the design process, not after. According to the cognitive theory of reflection-in-action, designers can evaluate their designs best during the design process rather than at its end (Schon 1983). Moreover, it also provides a means to show the consequences of design decisions and detect design errors.

Beginning from the high category of the UKRs, the process of evaluation can be first applied to counter design by selecting and right-clicking on it in the SkectchUp drawing area. Each of the six 'Priority Check' interfaces is a text-based dialog box that consists of two parts: an information area and a checkbox area (Figure 11). The information area displays the priority category of the selected requirement feature and its correlated requirement priorities in order to give designers a relationship-based view of evaluations and simultaneously track improvements 


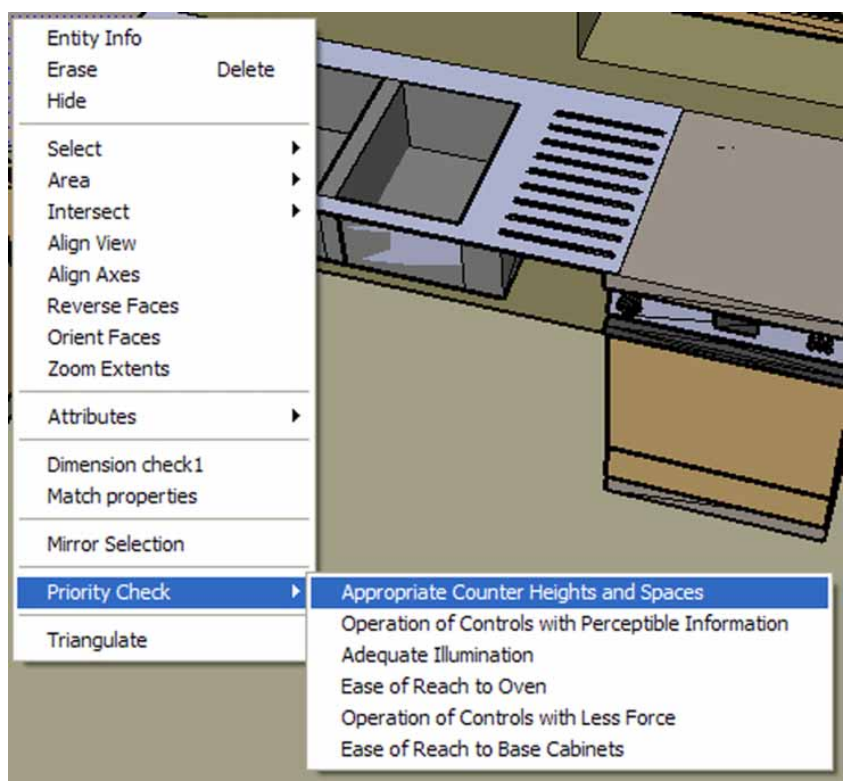

Figure 10. The 'Priority Check' interface with the six sub-menu items corresponding to the six UKRs.

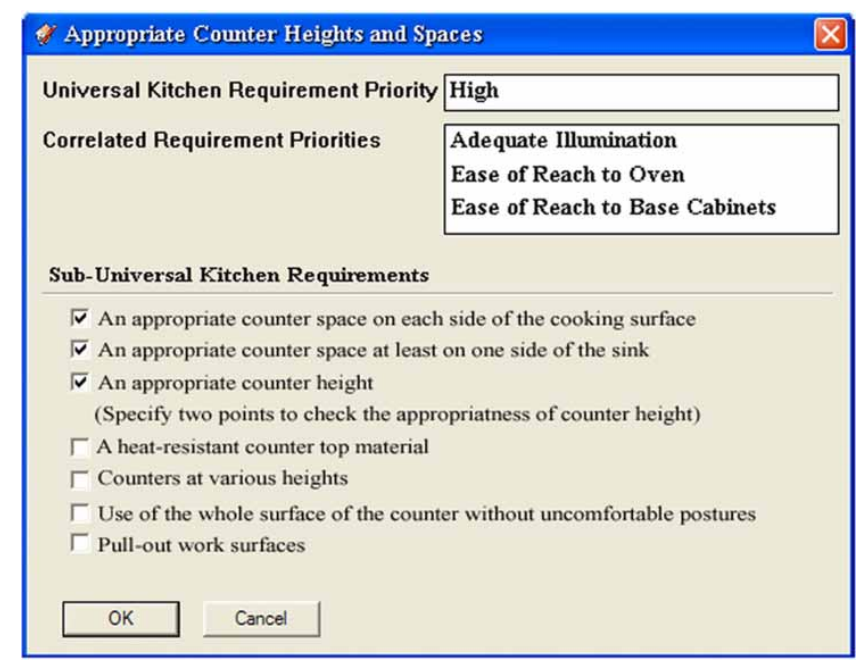

Figure 11. The 'Priority Check' interface of 'Appropriate counter heights and spaces'.

in the correlated requirements. This relationship-based view in the information area keeps designers informed about which requirements are in conflict with each other and which are not. The checkbox area allows designers to go through each sub-UKR and check whether or not they are satisfied. Ticks in the boxes represent the designer's decision as to whether a kitchen feature has met these requirements. Moreover, if there is a dimension-related requirement among the sub-UKRs, the interface automatically pops up a dialog box to check the appropriateness. The dialog box asks the designer to specify two points of the kitchen feature. By clicking the 'OK' button, she/he is prompted to move the cursor in the direction to be measured so that 
any two points of the kitchen feature are selected and dynamically evaluated against whatever universal design dimensional standard has been defined for this feature. A message box pops up giving the measured and required dimensions. As illustrated in Figure 11, the designer can identify potential counter areas for improvement by using the 'Appropriate counter heights and spaces' interface. The priority category of designing appropriate counter heights and spaces is high and its correlated requirements are 'Adequate illumination', 'Ease of reach to oven' and 'Ease of reach to base cabinets'. Hence, having checked the counters, the three correlated requirements should also be examined since any modification to the counters has an effect on these requirements. Coming to evaluation of sub-UKRs, by checking an 'Appropriate counter height' requirement, the interface identifies that the counter height is $90 \mathrm{~cm}$, whereas it should be between 73 and $86 \mathrm{~cm}$. It should be decreased to meet the required dimensions. The priority check process is carried out until all the six UKRs are checked, their corresponding design features are modified and their correlated requirements are analysed. These successive priority check steps give feedback into the universal problem-solving process and lead the designer to focus on further developments and modifications of problematic kitchen design features that can remain unnoticed. Each of the six 'Priority Check' interfaces also guides designers to decide what to rework next.

\section{Discussion}

This study focused on the systematic presentation and manipulation of universal design requirement priorities that are essential for the satisfaction of diverse users' needs. A plug-in tool is developed and implemented in a universal kitchen case. It serves as a design medium for all universal design operations in the conceptual design phase rather than being an expensive drafting tool like the traditional CAD systems. Since user acceptance of a computer-based information system is the crucial factor in determining the success or failure of a system (Lucas 1975), the study considered designers' opinions about the plug-in tool in terms of its usefulness, clarity, efficiency, support and user satisfaction. The 'System Acceptance Questionnaire' (SAQ) developed at HUSAT Research Institute (Maguire 2001) is adapted to assess the user acceptance of the plug-in tool. The SAQ is conducted with 20 respondents (12 architects and 8 interior architects), who are professionals and using SketchUp software in an international architectural design company (for further details of the SAQ, sample group, procedure and results, see Afacan 2008b). The results of the acceptability studies and statistical analyses indicate that in general the plug-in tool is found useful (mean $=5.44)$, understandable (mean $=5.71)$, efficient $($ mean $=5.47)$, helpful (mean $=5.28)$ and satisfactory (mean $=5.94)$ to support and foster successful universal design solutions (mean results based on 7-point rating scale).

All the respondents have positive opinions about the tool. They stated that the tool and its process are novel and have potential general applications for all inclusive design problems and/or general classes of design problems. The most favourite function of the plug-in tool is described by 10 of 20 respondents as the priority check. They stated that it is an essential interface that enables the reduction of error rates before the construction phase. Since the 'Priority Check' interface allows the assessment of design at various stages, it is possible to improve design solutions before the final decisions are made. Moreover, the respondents found the plug-in tool easy to learn and use. They were comfortable in adopting new functions of the plug-in tool and eager in utilising these functions while designing universal interior spaces in a SketchUp environment. Moreover, the respondents had suggestions for improvements in the plug-in tool. Especially, the interior architects (all of eight) wanted to have a developed version of this plug-in tool for bathrooms. They thought that it would be helpful in the universal bathroom design process. Table 5 illustrates some quotations from the semi-structured interviews of the respondents. 
Table 5. Some quotations from the semi-structured interviews of the respondents.

\begin{tabular}{ll}
\hline Respondent no. & Opinions about the plug-in tool \\
\hline Respondent 2 & $\begin{array}{l}\text { The tool could be developed to include universal design performance calculations of a kitchen solution } \\
\text { 'Pespondent } 8\end{array}$ \\
$\begin{array}{l}\text { 'Priority Manager' interface is an efficient solution for when we run into difficulties and spend time } \\
\text { accessing relevant priority information } \\
\text { 'Priority Check' interface helps designers to evaluate designs confidently and guides them efficiently } \\
\text { in making changes to fulfil requirements }\end{array}$ \\
Respondent 18 & \begin{tabular}{l} 
It would be great to have such a plug-in tool for other parts of a house, especially for a bathroom \\
\hline
\end{tabular} \\
\hline
\end{tabular}

\section{Conclusion}

Designers must consider a set of criteria for maximising the overall performance of a universal design solution for diverse user needs, capabilities and expectations. However, determining the optimal values for a set of user needs and design requirements is a complex and challenging task that requires expertise and extensive knowledge. In this respect, a priority-based approach with a holistic view is needed in order to manage the multiple criteria of universal design and their relevant priority information involving many decision attributes. The use of the PG and AHP techniques has the potential to reach better universal design solutions with more satisfied user needs. The proposed hybrid prioritisation technique does not only provide designers the relevant information on degrees of importance but also enables them to determine the weight and priority that should be given to each universal design feature. Furthermore, this study also highlighted the importance of a CAD tool support for understanding user needs, capabilities and expectations. As the study confirmed, achieving a successful computational medium for universal design necessitates CAD environments that are easy to understand, flexible enough to move around, able to provide a variety information and also enjoyable to work with. Mostly, a link to CAD systems is lacking or not addressed in the existing universal design practice in the architectural design context. Most CAD systems are successful in dealing with the geometric information (physical product modelling and geometric representation) rather than handling diverse user aspects of a kitchen design process. In this respect, the developed CAD systems are not well integrated into the problem-solving process of universal design and communication is not supported. However, the proposed plug-in tool provides technical knowledge of universal design as early as possible. Through the plug-in tool designers gain priority feedback in all design phases (analysis/synthesis/evaluation) that is both on time and relevant to their current design task.

To summarise, the priority-based approach for a universal kitchen is an initial design case supported by appropriate techniques and tools to answer the following two questions: (1) how can we increase the quality of life of people with different capabilities? And (2) what is the role of designers in this issue? This approach emphasises the significance of presenting diverse user needs in specific formats where designers can use them in the conceptual design phase. It is one of the first attempts that formally enable a universal design process to be assessed with respect to a prioritisation technique within a CAD environment. There are still many questions related to the use of this or similar processes/techniques to inform the inclusive design community. The survey should be tested in different kitchen design contexts (workplace kitchen, council-owned social housing kitchen or kitchen in a care home) in order to determine the degree of generalisability of the findings and the sensitivity of the relationships between requirement priorities. The requirement priorities are not based on task analysis or frequency of activities. Further research involving task analysis can be conducted to determine the priorities of activities, which are highly important in the use of a kitchen. Future studies should involve advanced CAD systems that are based on more flexible and advanced design, drafting and communication technologies with improved features for interface designs. In that case, it would also be possible to extend the capabilities of the 
Table 6. Guidelines for future research.

\begin{tabular}{|c|c|}
\hline Guideline no. & Guideline definition \\
\hline 1 & $\begin{array}{l}\text { The system should attain the simplest interface with the least number of menu options and a suitable set } \\
\text { of commands to access, prioritise and manipulate the universal design data }\end{array}$ \\
\hline 2 & $\begin{array}{l}\text { The system should be flexible enough to allow customisation of interfaces based on changing situations } \\
\text { during the design process }\end{array}$ \\
\hline 3 & $\begin{array}{l}\text { The system should provide fast and intuitive ways to assist designers in defining and prioritising a set of } \\
\text { objectives of a project }\end{array}$ \\
\hline 4 & $\begin{array}{l}\text { The system should provide the ability to enter requirements and prioritisation specifications from the } \\
\text { design brief and other sources }\end{array}$ \\
\hline 5 & The system should remind designers to complete requirement prioritisations that are in progress \\
\hline 6 & The system should allow to modify/specify/add new prioritisations to the initially stated ones \\
\hline 7 & $\begin{array}{l}\text { The system should allow designers to extract the universal design priority data easily and quickly, } \\
\text { such as dimensional standards, accessibility requirements, technical specifications, minimum code } \\
\text { requirements of universal design and design guidelines }\end{array}$ \\
\hline 8 & The total time spent on prioritisation and evaluation should be reduced \\
\hline 9 & $\begin{array}{l}\text { The system should give designers the possibility of richer interaction with other designers all over } \\
\text { the world, such as instant messaging, video calling, during their divergent and convergent thinking } \\
\text { activities }\end{array}$ \\
\hline 10 & $\begin{array}{l}\text { The system should provide additional data links to up-to-date web pages related to universal design } \\
\text { alternative solutions }\end{array}$ \\
\hline 11 & $\begin{array}{l}\text { The system should not interrupt the designer's creative process, i.e. should not design instead of the } \\
\text { designer }\end{array}$ \\
\hline 12 & $\begin{array}{l}\text { The system should provide user friendly menus including auditory, pictorial and textual universal design } \\
\text { data with necessary annotations and descriptions }\end{array}$ \\
\hline 13 & $\begin{array}{l}\text { The system should provide prioritisation means through which a designer can evaluate alternative } \\
\text { solutions both during and at the end of the universal design process }\end{array}$ \\
\hline 14 & $\begin{array}{l}\text { The system should give designers the opportunity to add sticky notes and comment boxes through which } \\
\text { the consequences of prioritisation evaluations can be shown for later referencing and backtracking }\end{array}$ \\
\hline 15 & The system should provide rapid priority feedback to check how far each requirement priority is satisfied \\
\hline 16 & $\begin{array}{l}\text { The system should evaluate the universal design performance of the final solution against the best } \\
\text { universal design priorities }\end{array}$ \\
\hline
\end{tabular}

plug-in tool for other interior spaces, especially for bathrooms as suggested by the respondents in the acceptability studies. Hence, the authors are still working on a further developed version of the plug-in tool that would be publicly downloadable from the Smustard-the Companion to Sketchup (TM) (2008, Smustard scripts [online], www.smustard.com: the existing version can be obtained by contacting with the authors). Future research can focus on the improvement of the priority-based approach for different design applications. The following guidelines involve recommendations for future researchers in developing a CAD tool for accommodating a variety of design interactions, universal design requirement dependencies, conflicts and feedbacks (Table 6).

\section{References}

Afacan, Y., 2008a. Designing for an aging population: residential preferences of the Turkish elderly to age in place. In: P. Langdon, P.J. Clarkson, and P. Robinson, eds. Designing inclusive futures. London: Springer-Verlag, pp. 241-252. Afacan, Y., 2008b. A computer assisted universal design (CAUD) plug-in tool for architectural design process [online]. Thesis (PhD). Bilkent University, Ankara, Turkey. Available from: http://bliss.bilkent.edu.tr/blissweb.php?islem=2\& dil=0\&d=bilkutup\&n=0405979 [Accessed 10 September 2008].

Afacan, Y. and Erbug, C., 2009. Application of heuristic evaluation method by universal design experts. Applied Ergonomics, 40 (4), 731-744.

Akin, O., 1986. Psychology of architectural design. London: Pion.

Bailey, K.D., 1994. Methods of social research. New York: The Free Press.

Beck, K., 1999. Extreme programming explained. Reading, MA: Addison-Wesley.

Beecher, V. and Paquet, V., 2005. Survey instrument for the universal design of consumer products. Applied Ergonomics, 36 (3), 363-372.

Byun, D.H., 2001. The AHP approach for selecting an automobile purchase model. Information and Management, 38 (5), 289-297. 
Canadian Human Rights Commission, 2006. International best practices in universal design: a global review. [CD-ROM]. Ottawa, ON: Canadian Human Rights Commission.

Carmichael, A., Newell, A.F., and Morgan, M., 2007. The efficacy of narrative video for raising awareness in ICT designers about older users' requirements. Interacting with Computers, 19 (5-6), 587-596.

Carrara, G., Kalay, Y.E., and Novembri, G., 1994. Knowledge-based computational support for architectural design. In: G. Carrara and Y.E. Kalay, eds. Knowledge-based computer-aided architectural design. Amsterdam: Elsevier, 147-204.

Choi, Y.S., et al. 2006. Are 'universal design resources' designed for designers. In: Proceedings ASSETS' 06, 23-25 October, Portland, Oregon. New York: ACM Press, 87-94.

Clarkson, P.J. and Hamilton, J.R., 2000. 'Signposting', a parameter-driven task-based model of the design process. Research in Engineering Design, 12 (1), 18-38.

Clarkson, P.J., et al., 2007. Inclusive design toolkit. UK: Cambridge Engineering Design Center Press.

Cross, N., 1989. Engineering design methods. Chichester, UK: John Wiley \& Sons.

Darses, F. and Wolff, M., 2006. How do designers represent to themselves the users' needs? Applied Ergonomics, 37 (1), 757-764.

Demirbilek, N. and Demirkan, H., 2004. Universal product design involving elderly users: a participatory design model. Applied Ergonomics, 35 (4), 361-370.

Demirkan, H., 2007. Housing for the aging population. European Review of Aging and Physical Activity, 4 (1), 33-38.

Eastman, C.M., 1999. Building product models: computer environments supporting design and construction. New York: CRC Press LLC.

Goldsmith, S., 1997. Designing for the disabled the new paradigm. Oxford, UK: Architectural Press.

Goodman, J., et al., 2006. Increasing the uptake of inclusive design in industry. Gerontechnology, 5 (3), 140-149.

Gregor, P., Sloan, D., and Newell, A., 2005. Disability and technology: building barriers or creating opportunities. In: M. Zelkowitz, ed. Advances in computers. London: Elsevier, 284-346.

Grist, R.R., et al., 1996. Accessible design review guide: an ADAAG guide for designing and specifying spaces, buildings and sites. New York: McGraw-Hill.

Hayden, D., 1972. The grand domestic revolution. Cambridge, MA: MIT Press.

Holbrook, H., 1990. A scenario-based methodology for conducting requirements elicitation. ACM SIGSOFT, 15 (1), 95-104.

Howitt, D. and Cramer, D., 1999. An introduction to statistics in psychology: a complete guide for students. Upper Saddle River, NJ: Prentice Hall.

Isiklar, G. and Büyüközkan, G., 2007. Using a multi-criteria decision making approach to evaluate mobile phone alternatives. Computer Standards and Interfaces, 29 (2), 265-274.

Karlsson, J., 1996. Software requirements prioritizing. In: Proceedings of the 2 nd international conference on requirements engineering (ICRE' 96) 15-18 April, Colorado, USA. Colorado: IEEE CS Press, 110-116.

Karlsson, J. and Ryan, K., 1996. Supporting the selection of software requirements. In: Proceedings of the 8th International Workshop on Software Specification and Design (IWSSD' 96), 22-23 March, Schloss Velen, Germany. Wahington, DC: IEEE CS Press, 146-149.

Karlsson, J. and Ryan, K., 1997. A cost-value approach for prioritizing requirements. IEEE Software, 14 (5), 67-74.

Karlsson, J., Wohlin, C., and Regnell, B., 1998. An evaluation of methods for prioritizing software requirements. Information and Software Technology, 39 (14-15), 939-947.

Karlsson, L., et al. 2007. Pair-wise comparisons versus planning game partitioning: experiments on requirements prioritization techniques. Empirical Software Engineering, 12 (1), 3-33.

Krathwohl, D.R., 1997. Educational and social science research. 2nd ed. New York: Addison-Wesley.

Lawson, B., 1998. Towards a computer-aided architectural design process: a journey of several images. Computers in Industry, 35 (1), 47-57.

Leffingwell, D. and Widrig, D., 2000. Managing software requirements - a unified approach. Boston: Addison-Wesley.

Lehtola, L. and Kauppinen, M., 2006. Suitability of requirements prioritization methods for market-driven software product development. Software Process Improvement and Practice, 11 (1), 7-19.

Lehtola, L., Kauppinen, M., and Kujala, S., 2004. Requirements prioritization challenges in practice. In: Proceedings of 5th international conference on product focused software process improvement, 5-8 April, Kansai Science City, Japan. Beriln, Germany: Springer-Verlag, 497-508.

Levine, D., ed., 2006. Universal design New York 2. New York: IDEA Publication.

Lin, M., et al., 2008a. Using AHP and TOPSIS approaches in customer-driven product design process. Computers in Industry, 59 (1), 17-31.

Lin, C.C., Wang, W., and Yu, W., 2008b. Improving AHP for construction with an adaptive AHP approach (A3). Automation in Construction, 17 (2), 180-187.

Liu, F.X., 1998. A quantitative approach for assessing the priorities of software quality requirements. The Journal of Systems and Software, 42 (2), 105-113.

Lucas, H.C., 1975. Performance and the use of an information system. Management Science, 21 (8), 908-919.

Maguire, M., 2001. System acceptance questionnaire (SAQ) [online]. HUSAT Research Institute. Available from: http://www.lboro.ac.uk/research/esri/hfdc/index.htm [Accessed 5 January 2008].

Margaritis, S. and Marmaras, N., 2007. Supporting the design of office layout meeting ergonomics requirements. Applied Ergonomics, 38 (6), 781-790.

Mullick, A. and Levine, D., 2001. Universal kitchens and appliances. In: F.E.W. Preiser and E. Ostroff, eds. Universal design handbook. New York: McGraw-Hill, 41.1-41.18. 
Ostroff, E., 2001. Universal design: the new paradigm. In: F.E.W. Preiser and E. Ostroff, eds. Universal design handbook. New York: McGraw-Hill, 1.1-1.12.

Ozkaya, I. and Akin, O., 2006. Requirement-driven design: assistance for information traceability in design computing. Design Studies, 27 (3), 381-398.

Pinto, M.R., et al., 2000. Ergonomics, gerontechnology, and design for the home-environment. Applied Ergonomics, 31 (3), 317-322.

Saaty, T.L., 1980. Multicriteria decision making: the analytic hierarchy process. Pittsburgh, PA: RWS Publications.

Schon, D., 1983. The reflective practitioner: how professionals think in action. New York: Basic Books.

Smustard-the Companion to Sketchup (TM), 2008. Smustard scripts [online]. Available from: www.smustard.com [Accessed 1 December 2008].

Story, M.F., 2001. Principles of universal design. In: F.E.W. Preiser and E. Ostroff, eds. Universal design handbook. New York: McGraw-Hill, 10.1-10.11.

Story, M.F., Mueller, J.L., and Mace, R.L., 1998. The universal design file: designing for people of all ages and abilities. North Carolina State University Press.

The Center for Universal Design, 1997. Principles of universal design [online]. Available from: http://www.design.ncsu. edu/cud/about_ud/udprinciplestext.htm [Accessed 19 September 2009].

The Center for Universal Design, 2000. Affordable and universal homes: a plan book. Chapel Hill: NC State University Press.

The Center for Universal Design, 2007a. Residential rehabilitation, remodelling and universal design [online]. Available from: www.design.ncsu.edu/cud/ [Accessed 23 September 2003].

The Center for Universal Design, 2007b. Gold, silver and bronze universal design features in houses [online]. Available from: www.design.ncsu.edu/cud/ [Accessed 23 September 2003]

Vaidya, O.S. and Kumar, S., 2006. Analytic hierarchy process: an overview of applications. European Journal of Operational Research, 169 (1), 1-29.

Wellcome Home Project, 2007. Universal kitchen design [online]. Available from: http://www.bsu.edu/wellcomehome/ friendly_kitchen.html [Accessed 19 September 2009].

Wiegers, K., 1999. Software requirements. Redmond, WA: Microsoft Press.

Young, L.C. and Pace, R.J., 2001. The next-generation universal home. In: F.E.W. Preiser and E. Ostroff, eds. Universal design handbook. New York: McGraw-Hill, 34.1-34.21.

Zhang, Q. and Nishimura, T., 1996. A method of evaluation for scaling in the analytical hierarchy process. In: Proceedings of the IEEE international conference on systems, man and cybernetics, 14-17 October, Beijing, China. Wahington, DC: IEEE CS Press, Vol. 3, 1888-1893.

\section{Appendix 1. The survey instrument}

This survey aims to identify the kitchen needs of diverse user groups (adult, elderly, people with physical and visual disabilities). It lists the design features for a kitchen. Please rate your importance level for each feature on a scale of 1-5 ( 1 being the least important and 5 the most important) and mark the appropriate boxes to identify how important each of the following features is in working successfully within a kitchen environment.

Age:

Disability type:

Gender:

Education level:

User Group:

Female

Adult
C

C
Male

Elderly
C

C Disabled

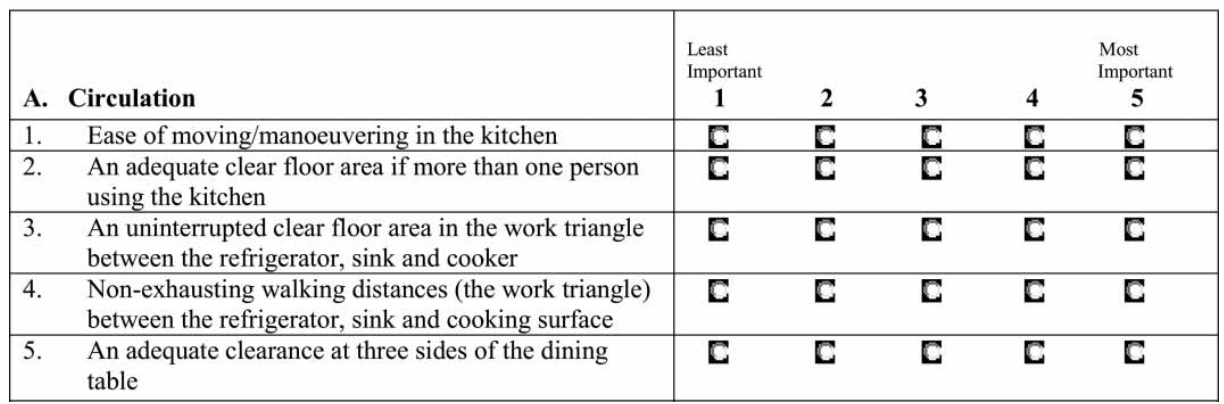




\begin{tabular}{|c|c|c|c|c|c|}
\hline B. Cabinets and storage areas & $\begin{array}{l}\text { Least } \\
\text { Important } \\
\quad \mathbf{1}\end{array}$ & 2 & 3 & 4 & $\begin{array}{l}\text { Most } \\
\text { Important } \\
\mathbf{5}\end{array}$ \\
\hline 6. Close access to the cabinets & $\mathbf{C}$ & $\mathbf{C}$ & $\mathbf{C}$ & $\mathbf{C}$ & $\mathbf{C}$ \\
\hline 7. Ease of reach to the low portions of the base cabinets & $\overline{\mathbf{C}}$ & $\overline{\mathbf{C}}$ & $\overline{\mathbf{C}}$ & C & $\mathbf{C}$ \\
\hline 8. Ease of reach to the high portions of the wall cabinets & $\bar{c}$ & $\overline{\mathbf{C}}$ & $\overline{\mathbf{C}}$ & C & $\overline{\mathbf{C}}$ \\
\hline 9. Ease of use of the rear portions of the base cabinets & $\bar{C}$ & $\overline{\mathbf{C}}$ & $\overline{\mathbf{C}}$ & $\overline{\mathbf{C}}$ & $\overline{\mathbf{C}}$ \\
\hline 10. Ease of use of the rear portions of the wall cabinets & $\bar{c}$ & $\overline{\mathbf{C}}$ & $\overline{\mathbf{C}}$ & $\overline{\mathrm{C}}$ & $\overline{\mathrm{C}}$ \\
\hline 11. Cabinets having pull-out shelves & $\mathbf{C}$ & $\mathbf{C}$ & $\mathbf{C}$ & $\mathbf{C}$ & $\mathbf{C}$ \\
\hline $\begin{array}{l}\text { 12. Effective and efficient use of corner cabinets by } 360^{\circ} \\
\text { rotating mechanisms/lazy-susan units/moon swing-out } \\
\text { shelves }\end{array}$ & $\mathbf{C}$ & C & $\mathbf{C}$ & $\mathbf{C}$ & $\mathbf{C}$ \\
\hline 13. Removable base cabinet doors & $\mathbf{C}$ & $\mathbf{C}$ & $\mathbf{C}$ & $\mathbf{C}$ & $\mathbf{C}$ \\
\hline 14. Use of the cabinet door handles with low effort & $\overline{\mathbf{C}}$ & $\overline{\mathbf{C}}$ & $\overline{\mathbf{C}}$ & $\overline{\mathbf{C}}$ & $\overline{\mathbf{C}}$ \\
\hline $\begin{array}{l}\text { 15. Use of the drawers and its contents without } \\
\text { uncomfortable postures }\end{array}$ & $\overline{\mathbf{C}}$ & $\overline{\mathbf{C}}$ & $\overline{\mathbf{C}}$ & $\overline{\mathbf{C}}$ & $\overline{\mathbf{C}}$ \\
\hline C. Counters/work surfaces & $\begin{array}{l}\text { Least } \\
\text { Important } \\
\quad 1\end{array}$ & 2 & 3 & 4 & $\begin{array}{l}\text { Most } \\
\text { Important } \\
\mathbf{5}\end{array}$ \\
\hline 16. Close access to the counter & $\mathbf{C}$ & $\mathbf{C}$ & $\mathbf{C}$ & $\mathbf{C}$ & $\mathbf{C}$ \\
\hline 17. An appropriate counter height & $\mathbf{C}$ & $\mathbf{C}$ & $\mathbf{C}$ & $\mathbf{C}$ & $\mathbf{C}$ \\
\hline $\begin{array}{l}\text { 18. Use of the whole surface of the counter without } \\
\text { uncomfortable postures }\end{array}$ & $\mathbf{C}$ & $\mathbf{C}$ & $\mathbf{C}$ & $\mathbf{E}$ & $\mathbf{C}$ \\
\hline 19. Counters at various heights & $\mathbf{C}$ & $\mathbf{C}$ & $\mathbf{C}$ & $\mathbf{C}$ & $\mathbf{C}$ \\
\hline 20. Pull-out work surfaces & $\overline{\mathbf{C}}$ & $\overline{\mathbf{C}}$ & $\overline{\mathbf{C}}$ & $\overline{\mathrm{C}}$ & $\overline{\mathbf{C}}$ \\
\hline $\begin{array}{l}\text { 21. An appropriate counter space on at least one side of } \\
\text { the refrigerator }\end{array}$ & $\overline{\mathbf{C}}$ & $\overline{\mathbf{C}}$ & $\overline{\mathbf{C}}$ & $\overline{\mathbf{C}}$ & $\overline{\mathbf{C}}$ \\
\hline $\begin{array}{l}\text { 22. An appropriate counter space on each side of the } \\
\text { cooking surface }\end{array}$ & $\mathbf{C}$ & $\mathbf{C}$ & $\mathbf{C}$ & $\mathbf{C}$ & $\mathbf{C}$ \\
\hline $\begin{array}{l}\text { 23. An appropriate counter space on at least one side of } \\
\text { the oven at the same level as the rack }\end{array}$ & $\mathbf{C}$ & $\mathbf{C}$ & $\mathbf{C}$ & $\mathbf{C}$ & $\mathbf{C}$ \\
\hline $\begin{array}{l}\text { 24. An appropriate counter space on at least one side of } \\
\text { the sink }\end{array}$ & $\mathbf{E}$ & $\mathbf{C}$ & $\mathbf{C}$ & $\mathbf{C}$ & C \\
\hline 25. Rounded edges on the counter & $\mathbf{C}$ & $\mathbf{C}$ & $\mathbf{C}$ & $\mathbf{E}$ & $\mathbf{C}$ \\
\hline D. Appliances & $\begin{array}{l}\text { Least } \\
\text { Important } \\
\mathbf{1}\end{array}$ & 2 & 3 & 4 & $\begin{array}{l}\text { Most } \\
\text { Important } \\
\mathbf{5}\end{array}$ \\
\hline 26. Close access to the refrigerator & $\mathbf{C}$ & $\mathbf{C}$ & $\mathbf{C}$ & $\mathbf{C}$ & C \\
\hline $\begin{array}{l}\text { 27. Ease of reach to all the essential elements of the } \\
\text { refrigerator from preferred positions }\end{array}$ & C & C & $\mathbf{C}$ & $\mathbf{C}$ & C \\
\hline 28. Availability of warning features on the refrigerator & $\mathbf{C}$ & $\mathbf{C}$ & $\mathbf{C}$ & $\mathbf{C}$ & $\mathbf{C}$ \\
\hline 29. Close access to the cook-top & $\mathbf{C}$ & $\mathbf{C}$ & $\mathbf{C}$ & $\mathbf{C}$ & $\mathbf{C}$ \\
\hline $\begin{array}{l}\text { 30. Ease of reach to all the essential elements of the cook- } \\
\text { top from preferred positions }\end{array}$ & $\mathbf{C}$ & $\mathbf{C}$ & $\mathbf{C}$ & $\mathbf{C}$ & $\mathbf{C}$ \\
\hline 31. Availability warning features on the cook-top & $\mathbf{C}$ & $\mathbf{C}$ & $\mathbf{C}$ & $\mathbf{C}$ & $\mathbf{C}$ \\
\hline 32. Close access to the oven & $\overline{\mathbf{C}}$ & $\overline{\mathbf{C}}$ & $\overline{\mathbf{E}}$ & $\overline{\mathbf{C}}$ & $\overline{\mathbf{C}}$ \\
\hline $\begin{array}{l}\text { 33. Ease of reach to all the essential elements of the oven } \\
\text { from preferred positions }\end{array}$ & $\overline{\mathbf{C}}$ & $\overline{\mathbf{C}}$ & $\overline{\mathbf{C}}$ & $\overline{\mathbf{C}}$ & $\mathbf{C}$ \\
\hline 34. Availability warning features on the oven & $\mathbf{C}$ & $\mathbf{C}$ & $\mathbf{C}$ & $\mathbf{C}$ & $\mathbf{C}$ \\
\hline 35. Close access to the dishwasher & $\mathbf{C}$ & $\mathbf{C}$ & $\mathbf{E}$ & $\mathbf{C}$ & $\mathbf{C}$ \\
\hline $\begin{array}{l}\text { 36. Ease of reach to all the essential elements of the } \\
\text { dishwasher from preferred positions }\end{array}$ & $\overline{\mathbf{C}}$ & $\overline{\mathbf{C}}$ & $\overline{\mathbf{C}}$ & $\overline{\mathbf{C}}$ & $\overline{\mathbf{C}}$ \\
\hline 37. Availability of warning features on the dishwasher & $\mathbf{C}$ & $\mathbf{C}$ & $\mathbf{C}$ & $\mathbf{C}$ & $\mathbf{C}$ \\
\hline 38. Close access to the hood & $\mathbf{E}$ & $\mathbf{E}$ & $\mathbf{C}$ & $\mathbf{C}$ & $\mathbf{C}$ \\
\hline $\begin{array}{l}\text { 39. Ease of reach to all the essential elements of the hood } \\
\text { from preferred positions }\end{array}$ & $\overline{\mathbf{C}}$ & $\overline{\mathbf{C}}$ & $\overline{\mathbf{C}}$ & $\overline{\mathbf{C}}$ & $\mathbf{E}$ \\
\hline 40. Availability of warning features on the hood & $\mathbf{C}$ & $\mathbf{C}$ & $\mathbf{E}$ & $\mathbf{C}$ & $\mathbf{C}$ \\
\hline
\end{tabular}




\begin{tabular}{|c|c|c|c|c|c|}
\hline E. Sink and faucets & $\begin{array}{l}\text { Least } \\
\text { Important } \\
\mathbf{1}\end{array}$ & $\mathbf{2}$ & 3 & 4 & $\begin{array}{l}\text { Most } \\
\text { Important } \\
\mathbf{5}\end{array}$ \\
\hline 41. Close access to the sink & $\mathbf{C}$ & $\mathbf{C}$ & $\mathbf{C}$ & C & $\mathbf{C}$ \\
\hline 42. Use of the sink without uncomfortable postures & $\overline{\mathbf{E}}$ & $\overline{\mathbf{C}}$ & $\overline{\mathbf{C}}$ & $\overline{\mathbf{E}}$ & $\overline{\mathbf{E}}$ \\
\hline 43. Ease of reach to the faucet from preferred positions & $\overline{\mathbf{C}}$ & $\overline{\mathbf{C}}$ & $\overline{\mathbf{C}}$ & $\overline{\mathbf{C}}$ & $\overline{\mathbf{C}}$ \\
\hline 44. Simple operation of faucet & $\overline{\mathbf{E}}$ & $\mathbf{E}$ & $\mathbf{E}$ & $\mathbf{E}$ & $\mathbf{E}$ \\
\hline 45. Operation of the faucet with low effort & $\mathbf{E}$ & $\mathbf{C}$ & $\mathbf{C}$ & $\mathbf{C}$ & $\mathbf{C}$ \\
\hline F. Controls (Sockets, switches and appliance controls) & $\begin{array}{l}\text { Least } \\
\text { Important } \\
1\end{array}$ & 2 & 3 & 4 & $\begin{array}{l}\text { Most } \\
\text { Important }\end{array}$ \\
\hline 46. Close access to the sockets & C & $\mathbf{C}$ & $\mathbf{E}$ & $\mathbf{c}$ & $\mathrm{C}$ \\
\hline 47. Operation of the sockets with low effort & $\overline{\mathbf{E}}$ & $\overline{\mathbf{C}}$ & $\overline{\mathbf{E}}$ & $\overline{\mathbf{C}}$ & $\overline{\mathbf{C}}$ \\
\hline $\begin{array}{l}\text { 48. Operation of the sockets without uncomfortable } \\
\text { postures }\end{array}$ & $\mathbf{C}$ & $\mathbf{E}$ & $\mathbf{E}$ & $\mathbf{E}$ & $\mathbf{E}$ \\
\hline 49. Operation of the sockets without sight & $\mathbf{E}$ & $\mathbf{C}$ & $\mathbf{E}$ & $\mathbf{E}$ & $\mathbf{E}$ \\
\hline 50. Close access to the switches & $\overline{\mathbf{C}}$ & $\overline{\mathbf{C}}$ & $\overline{\mathbf{C}}$ & $\overline{\mathbf{C}}$ & $\overline{\mathbf{E}}$ \\
\hline 51. Operation of the switches with low effort & $\overrightarrow{\mathrm{C}}$ & $\overline{\mathbf{C}}$ & $\overline{\mathbf{C}}$ & $\mathbf{E}$ & $\vec{E}$ \\
\hline $\begin{array}{l}\text { 52. Operation of the switches without uncomfortable } \\
\text { postures }\end{array}$ & $\overline{\mathrm{C}}$ & $\overline{\mathrm{C}}$ & C & $\bar{C}$ & $\bar{C}$ \\
\hline 53. Operation of the switches without sight & C & $\mathbf{E}$ & $\mathbf{E}$ & $\mathbf{C}$ & $\mathbf{C}$ \\
\hline 54. Close access to the refrigerator controls & $\mathbf{C}$ & $\vec{C}$ & C & C & $\mathbf{E}$ \\
\hline 55. Simple operation of refrigerator controls & $\overline{\mathbf{E}}$ & $\overline{\mathbf{C}}$ & $\overline{\mathbf{C}}$ & $\overline{\mathbf{E}}$ & $\overline{\mathbf{E}}$ \\
\hline $\begin{array}{l}\text { 56. Provision of helpful feedback by the refrigerator } \\
\text { controls while in use }\end{array}$ & $\overline{\mathbf{C}}$ & $\overline{\mathbf{C}}$ & $\overline{\mathbf{C}}$ & $\overline{\mathbf{C}}$ & $\overline{\mathbf{C}}$ \\
\hline 57. Operation of the refrigerator controls with low effort & $\mathbf{E}$ & $\mathbf{E}$ & $\mathbf{E}$ & $\mathbf{E}$ & $\mathbf{E}$ \\
\hline $\begin{array}{l}\text { 58. Operation of the refrigerator controls without } \\
\text { uncomfortable postures }\end{array}$ & $\mathbf{E}$ & $\mathbf{E}$ & $\mathbf{C}$ & $\mathbf{C}$ & $\mathbf{C}$ \\
\hline 59. Close access to the cook-top controls & E & $\mathbf{C}$ & $\mathbf{C}$ & $\mathbf{E}$ & $\mathbf{E}$ \\
\hline 60. Simple operation of cook-top controls & $\mathbf{C}$ & $\overline{\mathbf{C}}$ & $\mathbf{C}$ & E & $\overrightarrow{\mathbf{C}}$ \\
\hline $\begin{array}{l}\text { 61. Provision of helpful feedback by the cook-top controls } \\
\text { while in use }\end{array}$ & $\mathbf{C}$ & $\mathbf{E}$ & $\mathbf{E}$ & $\mathbf{E}$ & $\mathbf{E}$ \\
\hline 62. Operation of the cook-top controls with low effort & $\mathbf{E}$ & $\mathbf{E}$ & $\mathbf{E}$ & $\mathbf{E}$ & $\mathbf{E}$ \\
\hline $\begin{array}{l}\text { 63. Operation of the cook-top controls without } \\
\text { uncomfortable postures }\end{array}$ & $\overline{\mathbf{C}}$ & $\overline{\mathbf{C}}$ & $\overline{\mathbf{C}}$ & $\overline{\mathbf{C}}$ & $\overline{\mathbf{E}}$ \\
\hline 64. Close access to the oven controls & $\mathbf{E}$ & $\mathbf{E}$ & $\mathbf{E}$ & $\mathbf{E}$ & $\mathbf{E}$ \\
\hline 65. Simple operation of oven controls & $\overline{\mathbf{C}}$ & $\overline{\mathbf{C}}$ & $\overline{\mathbf{C}}$ & $\overline{\mathbf{E}}$ & $\overline{\mathbf{E}}$ \\
\hline $\begin{array}{l}\text { 66. Provision of helpful feedback by the oven controls } \\
\text { while in use }\end{array}$ & $\overline{\mathrm{C}}$ & $\overrightarrow{\mathrm{C}}$ & $\overline{\mathrm{C}}$ & $\mathbf{E}$ & $\mathbf{E}$ \\
\hline 67. Operation of the oven controls with low effort & E & $\mathbf{E}$ & $\mathbf{E}$ & $\mathbf{E}$ & $\mathbf{C}$ \\
\hline $\begin{array}{l}\text { 68. Operation of the oven controls without uncomfortable } \\
\text { postures }\end{array}$ & $\overline{\mathbf{C}}$ & $\overline{\mathbf{E}}$ & $\overline{\mathbf{E}}$ & $\overline{\mathbf{E}}$ & $\overline{\mathbf{E}}$ \\
\hline 69. Close access to the dishwasher controls & C & $\mathbf{C}$ & $\mathbf{C}$ & $\mathbf{C}$ & C \\
\hline 70. Simple operation of dishwasher controls & $\overline{\mathbf{E}}$ & $\overline{\mathbf{C}}$ & $\overline{\mathbf{E}}$ & $\overline{\mathbf{E}}$ & $\overline{\mathbf{E}}$ \\
\hline $\begin{array}{l}\text { 71. Provision of helpful feedback by the dishwasher } \\
\text { controls while in use }\end{array}$ & $\overline{\mathbf{C}}$ & $\overline{\mathbf{C}}$ & $\overline{\mathbf{C}}$ & $\overline{\mathbf{C}}$ & $\overline{\mathbf{C}}$ \\
\hline 72. Operation of the dishwasher controls with low effort & $\mathbf{C}$ & $\mathbf{C}$ & $\mathbf{C}$ & $\mathbf{E}$ & $\mathbf{E}$ \\
\hline $\begin{array}{l}\text { 73. Operation of the dishwasher controls without } \\
\text { uncomfortable postures }\end{array}$ & $\mathbf{E}$ & $\mathbf{E}$ & $\mathbf{E}$ & $\mathbf{E}$ & $\mathbf{E}$ \\
\hline 74. Close access to the hood controls & $\mathbf{E}$ & $\mathbf{C}$ & $\mathbf{E}$ & $\mathbf{E}$ & $\mathbf{E}$ \\
\hline 75. Simple operation of the hood controls & $\overrightarrow{\mathrm{C}}$ & $\overrightarrow{\mathbf{C}}$ & $\bar{C}$ & E & $\overrightarrow{\mathrm{C}}$ \\
\hline $\begin{array}{l}\text { 76. Provision of helpful feedback by the hood controls } \\
\text { while in use }\end{array}$ & $\mathbf{E}$ & $\mathbf{E}$ & $\mathbf{E}$ & $\mathbf{E}$ & $\mathbf{E}$ \\
\hline 77. Operation of the hood controls with low effort & $\mathbf{E}$ & $\mathbf{E}$ & $\mathbf{E}$ & $\mathbf{E}$ & $\mathbf{E}$ \\
\hline $\begin{array}{l}\text { 78. Operation of the hood controls without uncomfortable } \\
\text { postures }\end{array}$ & $\overline{\mathbf{C}}$ & $\overline{\mathbf{C}}$ & $\overline{\mathbf{E}}$ & $\overline{\mathbf{C}}$ & $\overline{\mathbf{C}}$ \\
\hline & $\begin{array}{l}\text { Least } \\
\text { Important }\end{array}$ & & & & $\begin{array}{l}\text { Most } \\
\text { Important }\end{array}$ \\
\hline G. Illumination & 1 & 2 & 3 & 4 & 5 \\
\hline 79. Adequate natural light in the kitchen & C & $\mathbf{C}$ & $\mathbf{C}$ & C & C \\
\hline 80. Adequate artificial light in the kitchen & C & $\mathbf{C}$ & C & C & $\mathrm{C}$ \\
\hline $\begin{array}{l}\text { 81. Adequate illumination levels over the working } \\
\text { surfaces }\end{array}$ & $\mathbf{E}$ & $\mathbf{E}$ & $\mathbf{E}$ & $\mathbf{E}$ & $\mathbf{E}$ \\
\hline 82. Adequate illumination levels above the cook-top & $\mathbf{E}$ & $\mathbf{C}$ & $\mathbf{E}$ & $\mathbf{E}$ & $\mathbf{E}$ \\
\hline
\end{tabular}




\begin{tabular}{|l|cccccc|}
\hline & & & & Most \\
H. Materials & $\begin{array}{l}\text { Least } \\
\text { Important } \\
\text { Important }\end{array}$ \\
\hline $83 . \quad$ A colour contrast between floor and counter material & $\mathbf{1}$ & $\mathbf{C}$ & $\mathbf{3}$ & $\mathbf{4}$ & $\mathbf{5}$ \\
\hline $84 . \quad$ A heat-resistant counter top material & $\mathbf{C}$ & $\mathbf{C}$ & $\mathbf{C}$ & $\mathbf{C}$ & $\mathbf{C}$ \\
\hline $85 . \quad$ A durable floor material & $\mathbf{C}$ & $\mathbf{C}$ & $\mathbf{C}$ & $\mathbf{C}$ & $\mathbf{C}$ \\
\hline $86 . \quad$ An easy-care floor material & $\mathbf{C}$ & $\mathbf{C}$ & $\mathbf{C}$ & $\mathbf{C}$ & $\mathbf{C}$ \\
\hline $87 . \quad$ A slip-resistant floor material & $\mathbf{C}$ & $\mathbf{C}$ & $\mathbf{C}$ & $\mathbf{C}$ & $\mathbf{C}$ \\
\hline
\end{tabular}

\section{Appendix 2.}

Table A1. The global weights of the sub-UKRs under the high PG category.

\begin{tabular}{|c|c|c|c|c|}
\hline UKR & Sub-UKRs & $\begin{array}{l}\text { Valu-cost } \\
\text { priority ratio }\end{array}$ & $\begin{array}{l}\text { Value, cost } \\
\text { weights }\end{array}$ & $\begin{array}{l}\text { Global value, } \\
\text { cost weights }\end{array}$ \\
\hline \multirow[t]{7}{*}{$\begin{array}{l}\text { Appropriate counter heights } \\
\text { and spaces, high ratio } \\
(0.786,0274)\end{array}$} & $\begin{array}{l}\text { Q22. An appropriate counter } \\
\text { space on each side of the } \\
\text { cooking surface }\end{array}$ & High ratio & $\begin{array}{l}0.305 \\
0.087\end{array}$ & $\begin{array}{l}0.305 \times 0.786=0.239 \\
0.087 \times 0.274=0.023\end{array}$ \\
\hline & $\begin{array}{l}\text { Q24. An appropriate counter } \\
\text { space on at least one side of } \\
\text { the sink }\end{array}$ & High ratio & $\begin{array}{l}0.191 \\
0.085\end{array}$ & $\begin{array}{l}0.191 \times 0.786=0.150 \\
0.085 \times 0.274=0.023\end{array}$ \\
\hline & $\begin{array}{l}\text { Q17. An appropriate counter } \\
\text { height }\end{array}$ & High ratio & $\begin{array}{l}0.175 \\
0.079\end{array}$ & $\begin{array}{l}0.175 \times 0.786=0.137 \\
0.079 \times 0.274=0.021\end{array}$ \\
\hline & $\begin{array}{l}\text { Q84. A heat-resistant counter } \\
\text { top material }\end{array}$ & Medium ratio & $\begin{array}{l}0.133 \\
0.176\end{array}$ & $\begin{array}{l}0.133 \times 0.786=0.104 \\
0.176 \times 0.274=0.048\end{array}$ \\
\hline & $\begin{array}{l}\text { Q19. Counters at various } \\
\text { heights }\end{array}$ & Medium ratio & $\begin{array}{l}0.056 \\
0.088\end{array}$ & $\begin{array}{l}0.056 \times 0.786=0.044 \\
0.088 \times 0.274=0.024\end{array}$ \\
\hline & $\begin{array}{l}\text { Q18. Use of the whole surface } \\
\text { of the counter without } \\
\text { uncomfortable postures }\end{array}$ & Low ratio & $\begin{array}{l}0.083 \\
0.275\end{array}$ & $\begin{array}{l}0.083 \times 0.786=0.065 \\
0.275 \times 0.274=0.075\end{array}$ \\
\hline & Q20. Pull-out work surfaces & Low ratio & $\begin{array}{l}0.057 \\
0.210\end{array}$ & $\begin{array}{l}0.057 \times 0.786=0.044 \\
0.210 \times 0.274=0.057\end{array}$ \\
\hline \multirow{8}{*}{$\begin{array}{l}\text { Operation of controls with } \\
\text { clear information, low ratio } \\
(0.214,0.725)\end{array}$} & $\begin{array}{l}\text { Q31. Availability of warning } \\
\text { features on the cook-top }\end{array}$ & High ratio & $\begin{array}{l}0.322 \\
0.121\end{array}$ & $\begin{array}{l}0.322 \times 0.214=0.068 \\
0.121 \times 0.725=0.087\end{array}$ \\
\hline & $\begin{array}{l}\text { Q25. Rounded edges on the } \\
\text { counter }\end{array}$ & High ratio & $\begin{array}{l}0.091 \\
0.023\end{array}$ & $\begin{array}{l}0.091 \times 0.214=0.019 \\
0.023 \times 0.725=0.016\end{array}$ \\
\hline & $\begin{array}{l}\text { Q61. Provision of helpful } \\
\text { feedback by the cook-top } \\
\text { controls while in use }\end{array}$ & Medium ratio & $\begin{array}{l}0.208 \\
0.235\end{array}$ & $\begin{array}{l}0.208 \times 0.214=0.044 \\
0.235 \times 0.725=0.170\end{array}$ \\
\hline & $\begin{array}{l}\text { Q66. Provision of helpful } \\
\text { feedback by the oven } \\
\text { controls while in use }\end{array}$ & Medium ratio & $\begin{array}{l}0.123 \\
0.182\end{array}$ & $\begin{array}{l}0.123 \times 0.214=0.026 \\
0.182 \times 0.725=0.131\end{array}$ \\
\hline & $\begin{array}{l}\text { Q76. Provision of helpful } \\
\text { feedback by the hood } \\
\text { controls while in use }\end{array}$ & Medium ratio & $\begin{array}{l}0.112 \\
0.169\end{array}$ & $\begin{array}{l}0.112 \times 0.214=0.023 \\
0.169 \times 0.725=0.122\end{array}$ \\
\hline & $\begin{array}{l}\text { Q37. Availability of warning } \\
\text { features of the dishwasher }\end{array}$ & Medium ratio & $\begin{array}{l}0.069 \\
0.103\end{array}$ & $\begin{array}{l}0.069 \times 0.214=0.014 \\
0.103 \times 0.725=0.074\end{array}$ \\
\hline & $\begin{array}{l}\text { Q56. Provision of helpful } \\
\text { feedback by the refrigerator } \\
\text { controls while in use }\end{array}$ & Medium ratio & $\begin{array}{l}0.034 \\
0.089\end{array}$ & $\begin{array}{l}0.034 \times 0.214=0.007 \\
0.089 \times 0.725=0.064\end{array}$ \\
\hline & $\begin{array}{l}\text { Q28. Availability of warning } \\
\text { features on the refrigerator }\end{array}$ & Medium ratio & $\begin{array}{l}0.041 \\
0.078\end{array}$ & $\begin{array}{l}0.041 \times 0.214=0.008 \\
0.078 \times 0.725=0.056\end{array}$ \\
\hline
\end{tabular}


Table A2. The global weights of the sub-UKRs under the medium PG category.

\begin{tabular}{|c|c|c|c|c|}
\hline UKR & Sub-UKRs & $\begin{array}{l}\text { Valu-cost } \\
\text { priority ratio }\end{array}$ & $\begin{array}{l}\text { Value, cost } \\
\text { weights }\end{array}$ & $\begin{array}{l}\text { Global value, } \\
\text { cost weights }\end{array}$ \\
\hline \multirow[t]{4}{*}{$\begin{array}{l}\text { Adequate illumination, high } \\
\quad \text { ratio }(0.750,0.750)\end{array}$} & $\begin{array}{l}\text { Q82. Adequate illumination } \\
\text { level above the cook-top }\end{array}$ & High ratio & $\begin{array}{l}0.493 \\
0.146\end{array}$ & $\begin{array}{l}0.493 \times 0.750=0.369 \\
0.146 \times 0.750=0.109\end{array}$ \\
\hline & $\begin{array}{l}\text { Q79. Adequate natural light } \\
\text { in the kitchen }\end{array}$ & High ratio & $\begin{array}{l}0.119 \\
0.068\end{array}$ & $\begin{array}{l}0.119 \times 0.750=0.089 \\
0.068 \times 0.750=0.051\end{array}$ \\
\hline & $\begin{array}{l}\text { Q80. Adequate artificial light } \\
\text { in the kitchen }\end{array}$ & Medium ratio & $\begin{array}{l}0.130 \\
0.271\end{array}$ & $\begin{array}{l}0.130 \times 0.750=0.097 \\
0.271 \times 0.750=0.203\end{array}$ \\
\hline & $\begin{array}{l}\text { Q81. Adequate illumination } \\
\text { level over the working } \\
\text { surfaces }\end{array}$ & Medium ratio & $\begin{array}{l}0.258 \\
0.515\end{array}$ & $\begin{array}{l}0.258 \times 0.750=0.193 \\
0.515 \times 0.750=0.386\end{array}$ \\
\hline \multirow[t]{3}{*}{$\begin{array}{l}\text { Ease of reach to oven, high } \\
\quad \text { ratio }(0.250,0.250)\end{array}$} & $\begin{array}{l}\text { Q23. An appropriate counter } \\
\text { space at least on one side of } \\
\text { the oven at the same level } \\
\text { as the rack }\end{array}$ & High ratio & $\begin{array}{l}0.409 \\
0.132\end{array}$ & $\begin{array}{l}0.409 \times 0.250=0.102 \\
0.132 \times 0.250=0.033\end{array}$ \\
\hline & $\begin{array}{l}\text { Q32. Close approach to the } \\
\text { oven }\end{array}$ & Medium ratio & $\begin{array}{l}0.385 \\
0.317\end{array}$ & $\begin{array}{l}0.385 \times 0.250=0.096 \\
0.317 \times 0.250=0.079\end{array}$ \\
\hline & $\begin{array}{l}\text { Q33. Ease of reach to all } \\
\text { the essential elements of } \\
\text { the oven from preferred } \\
\text { positions }\end{array}$ & Low ratio & $\begin{array}{l}0.206 \\
0.551\end{array}$ & $\begin{array}{l}0.206 \times 0.250=0.051 \\
0.551 \times 0.250=0.137\end{array}$ \\
\hline
\end{tabular}

Table A3. The global weights of the sub-UKRs under the low PG category.

\begin{tabular}{|c|c|c|c|c|}
\hline UKR & Sub-UKRs & $\begin{array}{l}\text { Valu-cost } \\
\text { priority ratio }\end{array}$ & $\begin{array}{l}\text { Value, cost } \\
\text { weights }\end{array}$ & $\begin{array}{l}\text { Global value, } \\
\text { cost weights }\end{array}$ \\
\hline \multirow{11}{*}{$\begin{array}{l}\text { Operation of controls with } \\
\text { low effort, high ratio } \\
(0.257,0.234)\end{array}$} & $\begin{array}{l}\text { Q47. Operation of the sockets } \\
\text { with low effort }\end{array}$ & Medium ratio & $\begin{array}{l}0.237 \\
0.199\end{array}$ & $\begin{array}{l}0.237 \times 0.257=0.060 \\
0.199 \times 0.234=0.046\end{array}$ \\
\hline & $\begin{array}{l}\text { Q67. Operation of the oven } \\
\text { controls with low effort }\end{array}$ & Medium ratio & $\begin{array}{l}0.095 \\
0.122\end{array}$ & $\begin{array}{l}0.095 \times 0.257=0.024 \\
0.122 \times 0.234=0.028\end{array}$ \\
\hline & $\begin{array}{l}\text { Q65. Simple operation of } \\
\text { oven controls }\end{array}$ & Medium ratio & $\begin{array}{l}0.092 \\
0.114\end{array}$ & $\begin{array}{l}0.092 \times 0.257=0.023 \\
0.114 \times 0.234=0.026\end{array}$ \\
\hline & $\begin{array}{l}\text { Q14. Use of the cabinet door } \\
\text { handles with low effort }\end{array}$ & Medium ratio & $\begin{array}{l}0.084 \\
0.106\end{array}$ & $\begin{array}{l}0.084 \times 0.257=0.021 \\
0.106 \times 0.234=0.024\end{array}$ \\
\hline & $\begin{array}{l}\text { Q60: Simple operation of } \\
\text { cook-top controls }\end{array}$ & Medium ratio & $\begin{array}{l}0.125 \\
0.084\end{array}$ & $\begin{array}{l}0.125 \times 0.257=0.032 \\
0.084 \times 0.234=0.011\end{array}$ \\
\hline & $\begin{array}{l}\text { Q45. Operation of the faucet } \\
\text { with low effort }\end{array}$ & Medium ratio & $\begin{array}{l}0.067 \\
0.087\end{array}$ & $\begin{array}{l}0.067 \times 0.257=0.017 \\
0.087 \times 0.234=0.020\end{array}$ \\
\hline & $\begin{array}{l}\text { Q57. Operation of the } \\
\text { refrigerator controls with } \\
\text { low effort }\end{array}$ & Medium ratio & $\begin{array}{l}0.048 \\
0.049\end{array}$ & $\begin{array}{l}0.048 \times 0.257=0.012 \\
0.049 \times 0.234=0.011\end{array}$ \\
\hline & $\begin{array}{l}\text { Q55. Simple operation of } \\
\text { refrigerator controls }\end{array}$ & Medium ratio & $\begin{array}{l}0.045 \\
0.042\end{array}$ & $\begin{array}{l}0.045 \times 0.257=0.012 \\
0.042 \times 0.234=0.009\end{array}$ \\
\hline & $\begin{array}{l}\text { Q62. Operation of the } \\
\text { cook-top controls with low } \\
\text { effort }\end{array}$ & Medium ratio & $\begin{array}{l}0.107 \\
0.106\end{array}$ & $\begin{array}{l}0.107 \times 0.257=0.013 \\
0.106 \times 0.234=0.024\end{array}$ \\
\hline & $\begin{array}{l}\text { Q44. Simple operation of } \\
\text { faucet }\end{array}$ & Medium ratio & $\begin{array}{l}0.051 \\
0.047\end{array}$ & $\begin{array}{l}0.051 \times 0.257=0.013 \\
0.047 \times 0.234=0.010\end{array}$ \\
\hline & $\begin{array}{l}\text { Q51. Operation of the } \\
\text { switches with low effort }\end{array}$ & Medium ratio & $\begin{array}{l}0.049 \\
0.044\end{array}$ & $\begin{array}{l}0.049 \times 0.257=0.012 \\
0.044 \times 0.234=0.010\end{array}$ \\
\hline
\end{tabular}


Table A3. Continued

\begin{tabular}{|c|c|c|c|c|}
\hline UKR & Sub-UKRs & $\begin{array}{l}\text { Value-cost } \\
\text { priority ratio }\end{array}$ & $\begin{array}{l}\text { Value, cost } \\
\text { weights }\end{array}$ & $\begin{array}{l}\text { Global value, } \\
\text { cost weights }\end{array}$ \\
\hline \multirow[t]{3}{*}{$\begin{array}{l}\text { Ease of reach to base cabinets, } \\
\text { high ratio }(0.743,0.766)\end{array}$} & $\begin{array}{l}\text { Q7. Ease of reach to the } \\
\text { portions of the base } \\
\text { cabinets }\end{array}$ & High ratio & $\begin{array}{l}0.303 \\
0.115\end{array}$ & $\begin{array}{l}0.303 \times 0.743=0.433 \\
0.115 \times 0.766=0.088\end{array}$ \\
\hline & $\begin{array}{l}\text { Q12. Effective and efficient } \\
\text { use of corner cabi- } \\
\text { nets by } 360^{\circ} \text { rotating } \\
\text { mechanism/lazy-susan } \\
\text { units/moon swing-out } \\
\text { shelves }\end{array}$ & Medium ratio & $\begin{array}{l}0.584 \\
0.468\end{array}$ & $\begin{array}{l}0.584 \times 0.743=0.433 \\
0.468 \times 0.766=0.358\end{array}$ \\
\hline & $\begin{array}{l}\text { Q9. Ease of use the rear } \\
\text { portions of the base } \\
\text { cabinets }\end{array}$ & Low ratio & $\begin{array}{l}0.113 \\
0.417\end{array}$ & $\begin{array}{l}0.113 \times 0.743=0.433 \\
0.417 \times 0.766=0.319\end{array}$ \\
\hline
\end{tabular}

